\title{
Reliability of equivalent-dose determination and age-models in the OSL dating of historical and modern palaeoflood sediments
}

Medialdea, Alicia; Thomsen, Kristina Jørkov; Murray, Andrew Sean; Benito, G.

Published in:

Quaternary Geochronology

Link to article, DOI:

10.1016/j.quageo.2014.01.004

Publication date:

2014

Document Version

Peer reviewed version

Link back to DTU Orbit

Citation (APA):

Medialdea, A., Thomsen, K. J., Murray, A. S., \& Benito, G. (2014). Reliability of equivalent-dose determination and age-models in the OSL dating of historical and modern palaeoflood sediments. Quaternary Geochronology, 22, 11-24. https://doi.org/10.1016/j.quageo.2014.01.004

\section{General rights}

Copyright and moral rights for the publications made accessible in the public portal are retained by the authors and/or other copyright owners and it is a condition of accessing publications that users recognise and abide by the legal requirements associated with these rights.

- Users may download and print one copy of any publication from the public portal for the purpose of private study or research.

- You may not further distribute the material or use it for any profit-making activity or commercial gain

- You may freely distribute the URL identifying the publication in the public portal 


\section{Elsevier Editorial System(tm) for Quaternary Geochronology Manuscript Draft}

\section{Manuscript Number: QUAGEO-D-12-00096R1}

Title: Reliability of equivalent-dose determination and age-models in the OSL dating of historical and modern palaeoflood sediments

Article Type: Research Paper

Keywords: Optically stimulated luminescence, quartz, flash-flood deposits, young sediments, minimum age models, single grains

Corresponding Author: Ms. Alicia Medialdea,

Corresponding Author's Institution: CSIC

First Author: Alicia Medialdea

Order of Authors: Alicia Medialdea; Kristina J Thomsen; Andrew S Murray; Gerardo Benito

Abstract: The challenge of accurately estimating the deposition age of incompletely-bleached samples in luminescence dating has motivated developments in the analysis of single grain dose distributions, and a number of statistical approaches have been proposed over the last few years. In this study, we compare the behaviour of the arithmetic average, the so-called 'robust statistics', the Central Age Model (CAM), the Minimum Age Model (MAM) and the Internal-External Consistency Criterion (IEU), when applied to single-grain and small multi-grain ( $\sim 30$ grains per aliquot) dose distributions from a sequence of eight recent (40-1000 years old) flash-flood deposits. These sediments are expected to be incompletely bleached, but all have age control from historical records. Modifications were made to allow the use of the standard CAM and MAM models with dose distributions containing near zero and negative dose values. An assessment of minimum uncertainty on individual dose estimates is based on the over-dispersion (OD) determined in dose recovery tests making use of gamma-irradiated samples. We then present a detailed analysis of the impact of appropriate uncertainty assignment on minimum (MAM and IEU) burial dose estimates. The results of the various models are discussed in terms of the accuracy of the resulting age, and we conclude that, overall, the IEU approach generates the most accurate ages. We also demonstrate that accurate IEU ages can be obtained from multi-grain measurements if an age off-set of $\sim 40$ years can be considered to be unimportant for the samples in question. From our study we conclude that these and similar young slack-water flood deposits can be accurately dated using quartz OSL, opening up the possibility of establishing time series of flood discharge in catchments for which no instrumental or historical record exists. 
1 Reliability of equivalent-dose determination and age-models in the OSL dating of

2 historical and modern palaeoflood sediments

$4 \quad$ Medialdea ${ }^{1,3}$, A., Thomsen², K.J., Murray ${ }^{3}$, A.S., Benito ${ }^{1}$, G.

5 1. Museo Nacional de Ciencias Naturales, CSIC, Serrano 115bis, 28006 Madrid, $6 \quad$ Spain. amedialdea@mncn.csic.es

7 2. Center for Nuclear Technologies, Technical University of Denmark, DTU Risø 8 Campus, Frederiksborgvej 399, 4000 Roskilde, Denmark.

9 3. Nordic Laboratory for Luminescence Dating, Department of Earth Sciences, Århus 10 University, Risø, Frederiksborgvej 399, 4000 Roskilde, Denmark

12 Abstract

13 The challenge of accurately estimating the deposition age of incompletely-bleached samples in luminescence dating has motivated developments in the analysis of single grain dose distributions, and a number of statistical approaches have been proposed over the last few years. In this study, we compare the behaviour of the arithmetic average, the so-called 'robust statistics', the Central Age Model (CAM), the Minimum Age Model (MAM) and the Internal-External Consistency Criterion

19 (IEU), when applied to single-grain and small multi-grain ( $\sim 30$ grains per aliquot) dose distributions from a sequence of eight recent (40-1000 years old) flash-flood deposits. These sediments are expected to be incompletely bleached, but all have age control from historical records. Modifications were made to allow the use of the standard CAM and MAM models with dose distributions containing near zero and negative dose values. An assessment of minimum uncertainty on individual dose estimates is based on the over-dispersion (OD) determined in dose recovery tests 
26 making use of gamma-irradiated samples. We then present a detailed analysis of the 27 impact of appropriate uncertainty assignment on minimum (MAM and IEU) burial 28 dose estimates. The results of the various models are discussed in terms of the 29 accuracy of the resulting age, and we conclude that, overall, the IEU approach 30 generates the most accurate ages. We also demonstrate that accurate IEU ages can 31 be obtained from multi-grain measurements if an age off-set of $\sim 40$ years can be 32 considered to be unimportant for the samples in question. From our study we 33 conclude that these and similar young slack-water flood deposits can be accurately 34 dated using quartz OSL, opening up the possibility of establishing time series of 35 flood discharge in catchments for which no instrumental or historical record exists.

\section{Keywords}

38 Optically stimulated luminescence, quartz, flash-flood deposits, young sediments, 39 minimum age models, single grains. 
1. Introduction

41 Over the last decade optical dating has been increasingly used for dating Holocene fluvial deposits (e.g. Murray and Olley 2002; Wallinga, 2002; Wintle and Murray, 2006; Rittenour, 2008), complementing and extending the range of other dating techniques applicable to young deposits (e.g. radiocarbon and U-series dating). Sediments deposited by palaeofloods (Kochel and Baker, 1982) are of particular interest because they can provide high resolution records of extreme hydrological events occurring over short time periods, e.g. hours to days (Benito et al., 2004; Baker, 2008). These palaeoflood sediments are composed of stratigraphic sequences of fine-grained flood deposits emplaced in slack-water environments, usually within bedrock-controlled rivers; from these deposits the frequency and magnitude (palaeodischarge) of floods that occurred during recent centuries or millennia can be reconstructed. Palaeoflood hydrology has become important because using the stratigraphic evidence of former floods can extend the documentary record of extreme flood events considerably; this has direct application to flood hazard assessments and climate change research (Benito et al., 2004). Dating sedimentary flood units and interleaving deposits is a key task in supporting the analysis of temporal flood behaviour and recurrence (Benito and O'Connor, 2012).

In general, when dating sequences of sediments by luminescence, it is assumed that the sediment was exposed to sufficient light during transport prior to deposition to reset or bleach any latent luminescence signal. In the case of flood sediments, with short transport times and the possibility of limited light exposure, the accuracy of luminescence dating can be compromised if any latent luminescence was not completely reset during or shortly before transportation. This is likely to be a particular problem in the case of sediments transported by flash-floods (hydrographs lasting only few hours) over short distances in small basins $(<500$

$66 \mathrm{~km}^{2}$ ); these problems can be exacerbated by high turbidity levels or if the flood occurred at night. The consequence of such limited light exposure will be a deposit 
made up of a mixture of grains with different residual luminescence signals (and so apparent residual doses). These grains are said to be incompletely reset or partially bleached. The impact of these residual doses can be compounded by the effects of thermal transfer (Rhodes, 2000; Madsen and Murray, 2009) and both these effects can lead to overestimation of the burial dose. To address the problems related to partial bleaching several statistical minimum age models have been developed for data analysis; all are intended to determine the dose recorded by a postulated population of well-bleached grains contained within a population of incompletely bleached grains.

The aim of this study is to test the accuracy of OSL dating using poorly-bleached historical and modern palaeoflood sediments. Independent age control of the individual flood layers is provided by a complete documentary record of the most extreme floods in combination with a single radiocarbon age for the oldest unit measured using OSL. This data set has been used to test the ability of various statistical models to obtain accurate burial ages for young palaeoflood sediments. Specifically we apply descriptive and robust statistics, the Central Age Model (CAM, Galbraith et al., 1999), the Minimum Age Model (MAM, Galbraith, 2005), the unlogged Minimum Age Model (MAMur, Arnold et al., 2009) and the Internal-External Consistency Criteria (IEU, Thomsen et al., 2003; 2007) to both single-grain and small multi-grain ( $\sim 30$ grains) aliquot dose distributions. Single grain analysis is generally much more time consuming than multi-grain analysis (Rhodes, 2007) and it is therefore worthwhile testing whether single grain results are in fact superior to multi-grain results.

\section{Site description and age framework}

Sediment samples were taken from flood-related fluvial facies from the upper

3 Guadalentin River (upstream catchment area $372 \mathrm{~km}^{2}$ ) in south-eastern Spain (Figure

4 1). The sediment package consists of sand and silt flood sediments that accumulated 
from suspension during high stage floods in a slack-water environment. These slackwater flood sediments accumulated from many successive palaeofloods and now form an up to $7 \mathrm{~m}$ thick flood bench on the right margin of the Guadalentín River, $150 \mathrm{~m}$ upstream of a bedrock gorge entrance. At the Estrecho site, the stratigraphic section contains a very well-developed sequence of multiple fine-grained flood deposits, providing evidence of at least 24 individual flood layers deposited over the last 1000 years (Benito et al., 2010, Figure 1). Five of these have been radiocarbon dated using charcoal. Pretreatment of the sample material for radiocarbon dating was carried out by the ${ }^{14} \mathrm{C}$ laboratory of the Department of Geography at the University of Zurich (GIUZ). The AMS (accelerator mass spectrometry) measurement was made at the Institute of Particle Physics at the Swiss Federal Institute of Technology, Zurich (ETH). Calibration of the radiocarbon dates was carried out using the CalibeETH 1.5b (1991) program of the Institute for Intermediate Energy Physics ETH Zürich, Switzerland, using the calibration curves of Kromer and Becker (1993), Linnick et al. (1986) and Stuiver and Pearson (1993). The resulting ages are shown in Figure 1.

Unfortunately the resolution of the radiocarbon calibration curve over the last 200300 years prevents an accurate age determination of younger material, and so only the radiocarbon age for our oldest sample ( $\mathrm{T}-17$ corresponding to unit 20), lacking historical records, was used for comparison with OSL results (although it should be noted that a Bayesian age-depth model has been developed using the Oxcal radiocarbon calibration software for the ${ }^{14} \mathrm{C}$ chronology of this site, Thorndycraft et al., 2012). These deposits contain a record of all floods exceeding the elevation of the flood bench surface (main extreme floods) and so it is confidently expected that this sedimentary sequence should correlate well with the historically documented flood record in the village of Lorca, $30 \mathrm{~km}$ downstream. Although channel bed incision or aggradation cannot be completely ruled out in the reach from which samples were collected, the hydraulics and erosion base level of the channel thalweg are controlled 
123 by the bedrock gorge located downstream. Flow accelerates (velocity over $3 \mathrm{~m} / \mathrm{s}$ ) in

124 the bedrock gorge ( $25 \mathrm{~m}$ wide by $50 \mathrm{~m}$ high) and most of the deposits transported as

125 bed load are flushed downstream. There is no field evidence of aggradation over the

126 period of time covered in this paper, and the historical aerial photos since 1947

127 indicate a similar base level. We conclude that any channel bed changes in our study

128 reach must have been minor $( \pm 1 \mathrm{~m})$ and should not affect the general assumption of

129 this paper, i.e. that floods recorded in the stratigraphy correspond to extreme floods.

130 Based on these assumptions, Benito et al. (2010) assigned a flood year to each 131 palaeoflood unit recorded in the stratigraphy (Figure 1) on the basis of the 500-year 132 continuous record of extreme flooding (extracted from the Municipal Historical 133 Archive of Lorca); this record contains information on the flood date and duration, 134 casualties, inundated areas and damage to buildings, bridges and mills and to 135 agricultural land, with detailed reports on the income and expenditure of the community on flood damages (Benito et al., 2010; Machado et al., 2011). Based on the recorded socio-economic damage and the geomorphological implications, floods were classified into three categories (Barriendos and Coeur, 2004): (i) Ordinary floods - restricted to the channel section (discharge lower than the bankfull discharge). These do not reach overbank sites (damage only on those items located in the channel, e.g. mills, etc). (ii) Extraordinay floods - overflow onto floodplain areas but water depth and velocity are not enough to produce widespread destruction. (iii) Catastrophic floods - these produce overbank flow with high velocities, and considerable destruction of permanent infrastructure. Thus from the qualitative descriptions in the historical record, some flood magnitude component can be extracted. It is also likely that only floods classified as (ii) or (iii) are expected

147 to be recorded in the flood stratigraphy, but we must also consider possible sources 148 of error in this assumption.

149 Although sediment yield is important in relation to the thickness of the palaeoflood 150 units (not discussed in detail in this paper), it plays only a secondary role in the 
151 presence or otherwise of slack-water flood deposits. In contrast, flood stage 152 (discharge) plays a major role in the presence of a unit, because only floods 153 exceeding the elevation of the flood bench can lead to the deposition of a flood unit 154 (Benito and Thorndycraft, 2005). So the floods documented in the historical record are likely to have resulted in a sedimentary unit, but is that unit likely to have been

156 preserved?

157 Benito et al. (2010) point out that the depositional site and the textural characteristics

158 of the slack-water flood deposits indicate that the material was deposited in an eddy circulation during flood events. The breaks between flood units are horizontal and no erosive contacts have been identified in the sequence. Most of the units finish up with a fine laminae of silt or clay; these layers have usually been later bioturbated but their preservation indicates that the depositional environment is not prone to erosion even during major events. We conclude that it is very likely that (i) the historically recorded floods resulted in deposition, and (ii) that these depositional units had a high preservation potential.

166 During the period AD1500-1900, 31 flood events were reported in the Lorca Municipal Archive, of which 15 were classified as ordinary, 7 extraordinary and 9 catastrophic (Benito et al., 2010). During the second half of the 19th century, an increase in frequency of extraordinary and catastrophic floods is reflected both in the documentary record (with high economic losses and casualties) and in the palaeoflood record (with high energy sedimentary structures). As discussed in

172 Benito et al. (2010), the stratigraphic record at the Estrecho site contains flood layers with high-energy sedimentary structures (in units 17, 18, 21 and 22) matching the most extreme recent floods documented in the Lorca archive. The most severe

175 historical floods occurred in 1838 and 1879 and are assigned to units 18 and 21, 176 respectively. Between these floods, the stratigraphy shows at least two flood units 177 (units 19 and 20; the former $<7 \mathrm{~cm}$ in thickness) whereas the documentary records 178 contains only one catastrophic flood (1860); Benito et al. (2010) assigned an additional 
documented flood in 1877 (classified as ordinary from the Lorca record) to unit 20 to

180 account for this extra event. The largest flood at the end of the 19th Century occurred 181 in 1891, which was assigned to unit 22. The second largest flood in the 20th Century occurred in 1941 (palaeoflood unit 23) and the largest in 1973 (unit 24). These ages, assigned to each sedimentary flood unit on the bases of documentary written sources, are considered to provide good independent age control against which the robustness of OSL statistical age models can be tested.

\section{Methodology}

\subsection{Sample preparation and dose rate determination}

188 A total of eight stratigraphic units from the Estrecho site were sampled for OSL dating (Figure 1). Samples were wet sieved to grain size fractions $90-180 \mu \mathrm{m}$ and 180-250 $\mu \mathrm{m}$ and chemically treated to isolate the quartz fraction. Samples were treated with $10 \% \mathrm{HCl}$ until carbonates were dissolved, and then with $\mathrm{H}_{2} \mathrm{O}_{2}$ to remove organic matter. Density separation was not used on these samples; a solution of $40 \% \mathrm{HF}$ was used to dissolve all feldspar and to remove the outer quartz layer affected by alpha radiation. The samples were resieved after chemical treatment to give grains in the range 180-250 $\mu \mathrm{m}$. Feldspar contamination was tested for using IR simulation prior to OSL measurements; no detectable IRSL signal was observed.

Dose rates are based on the average radionuclide activities of material collected from the hole remaining after removal of the sampling tube. High resolution gamma spectrometry was used to measure concentrations of ${ }^{238} \mathrm{U},{ }^{232} \mathrm{Th}$ and ${ }^{40} \mathrm{~K}$ (Murray et al. 1987). Appropriate conversion factors (Olley et al., 1996) were then used to derive the dose rates. The site is well-drained and all deposits are well above the level of normal flow. The elevation of the river channel is related to the local base level; this is controlled by the bedrock gorge located $500 \mathrm{~m}$ downstream from the stratigraphic 
204 profile. As discussed above, only minor changes in the river level $(\sim 1 \mathrm{~m})$ are 205 considered likely.

206 It is assumed that the water content at the time of sampling is representative of the 207 average site water content. For simplicity a linear accumulation of deposits has been 208 assumed in order to calculate the contribution of cosmic radiation according to a 209 varying burial depth (based on Prescott \& Hutton, 1994). Sampling depths below 210 modern surface, observed water contents, radionuclide activity concentrations and 211 derived dry total dose rates to an infinite matrix are summarized in Table 1.

212 By combining the dose rate data with independent age control (see section 2) the 213 expected burial doses for each unit have been calculated from

214 These known ages and the corresponding expected doses are also summarized in 215 Table 1.

\section{$216 \quad 3.2 . \quad$ Instrumentation}

217 Quartz OSL measurements were made using automated Risø TL/OSL DA-20 218 luminescence readers (Bøtter-Jensen et al., 2010). Luminescence was detected using a 219 bialkali EMI 9235QB photomultiplier tube through a $7.5 \mathrm{~mm}$ Hoya U-340 filter. 220 Stimulation of multi-grain aliquots used a blue $(470 \pm 30 \mathrm{~nm})$ light emitting diode 221 array providing a stimulation power of $\sim 80 \mathrm{~mW} / \mathrm{cm}^{2}$ at the sample position. Grains 222 were mounted as a monolayer on $9.7 \mathrm{~mm}$ diameter stainless steel discs using silicone 223 oil. Single grain measurements used 180-250 $\mu \mathrm{m}$ diameter grains, and were 224 undertaken using the Risø single grain attachment (Duller et al., 1999; Bøtter-Jensen 225 et al., 2000). Single grains were loaded into aluminium discs containing 100 grain 226 holes, each with a depth and diameter of $300 \mu \mathrm{m}$. Optical stimulation used a $10 \mathrm{~mW}$ 227 green $(532 \mathrm{~nm}) \mathrm{Nd}: \mathrm{YVO}_{4}$ laser providing a power density of $\sim 50 \mathrm{~W} / \mathrm{cm}^{2}$ at the 228 stimulation position. 
Laboratory irradiations were undertaken using either in situ calibrated ${ }^{90} \mathrm{Sr} /{ }^{90} \mathrm{Y}$ beta sources (providing dose rates to quartz mounted on stainless steel discs of 0.04 to $0.11 \mathrm{~Gy} / \mathrm{s})$ or a ${ }^{137} \mathrm{Cs}(662 \mathrm{keV})$ collimated point gamma source in a scatter-free geometry (providing an accurately known dose rate in quartz of $\sim 30 \mu \mathrm{Gy} / \mathrm{s}$ ). Quartz grains were gamma irradiated in the dark in glass tubes (ID $=2.6 \mathrm{~mm}$ and wall 234 thickness $=1.8 \mathrm{~mm}$ ).

\subsection{OSL analysis method}

237 The quartz 180-250 $\mu \mathrm{m}$ fraction was chosen for all measurements as larger grain 238 sizes are expected to be better bleached than smaller grain sizes (Olley et al., 1998; 239 Colls et al., 2001; Truelsen et al., 2003; Fuchs et al., 2005) despite being expected to be 240 exposed to less light during transport (Wallinga, 2002). This is also the preferred 241 grain size for single grain measurements. Samples were measured using the SAR 242 procedure (Murray and Wintle, 2000; 2003) with three to five regeneration doses, a zero dose point to check recuperation of the signal after the highest regeneration

244 dose measurement cycle, and a recycling of the second regeneration dose. Our 245 protocol employed a preheat temperature of $200^{\circ} \mathrm{C}$ for $10 \mathrm{~s}$ and a cutheat of $180^{\circ} \mathrm{C}$ at a heating rate of $5^{\circ} \mathrm{C} / \mathrm{s}$ for all measurements (see section 4.3 ).

247 Multi-grain measurements were carried out using $2 \mathrm{~mm}$ aliquots containing 30 248 grains each. The number of grains on each aliquot was assessed under a microscope. 249 The OSL signals from multi-grain aliquots are based on the summation of the first $250 \quad 0.64 \mathrm{~s}$ of stimulation corrected for background derived from the following $0.64 \mathrm{~s}$ in order to eliminate the contribution of other components of smaller optical crosssections (Early BackGround subtraction, EBG, e.g. Cunningham and Wallinga, 2010).

253 Single-grain OSL signals are derived from the summation of the first $0.1 \mathrm{~s}$ of 254 stimulation less the sum of the last 0.2 s (i.e. Late BackGround subtraction, LBG). 
255 Using EBG on single grain measurements reduced the number of accepted grains by $256 \sim 30 \%$ without changing the dose estimate or over-dispersion significantly (see 257 section 5.1 .1 for further details) - this may reflect variable effective stimulation 258 power arising from reflection and scatter from grain surfaces (Thomsen et al., 2012). 259 Poisson statistics were assumed when estimating the uncertainty on the background260 corrected signal.

261 Dose estimates were accepted (both multi-grain and single grain measurements) if 262 the relative uncertainty on the natural test-dose response was less than $20 \%$ and if 263 the recycling value, excluding uncertainties of individual grains, was within $20 \%$ of 264 unity. Aliquots having a dose response curve with anomalous behaviour (e.g. 265 decreasing response for increasing dose) were also discarded ( $\sim 5 \%$ of the grains for 266 otherwise acceptable single grains, $<1 \%$ for multi-grain aliquots). These criteria led to 267 the rejection of $98 \%$ of the measured single grains and $\sim 5 \%$ of the multi-grain 268 aliquots. Doses and their uncertainties were estimated using Analyst 3.24 (Duller, 269 2007). Equivalent doses ( $\mathrm{D}_{\mathrm{e}}$ ) were estimated by interpolation of the natural test-dose270 corrected signal onto the dose response curve, fitted using either a linear or a saturating exponential function (see insets in Figure 2). Approximately $2 \%$ of the

272 measured sensitivity-corrected natural signals were higher than the signal measured 273 for the highest regeneration dose (70 Gy); in these cases the De was determined by 274 extrapolation. The uncertainties derived from Analyst 3.24 are based on counting 275 statistics and curve fitting errors. An additional uncertainty derived from gamma 276 dose recovery experiments was added onto individual dose estimates to account for 277 additional measureable intrinsic sources of variability (see section 4.4, Thomsen et 278 al., 2005, 2007, 2012; Reimann et al., 2012; Sim et al., 2012).

279 All single grain dose distributions, except those obtained after in situ beta 280 irradiation, were corrected for beta source inhomogeneity using the approach 281 described by Lapp et al. (2012, see section 4.5$)$. 


\subsection{Burial dose estimation}

283 To estimate the burial dose we use five different approaches:

284 (i) The simple unweighted arithmetic mean and standard deviation. In this case all 285 dose estimates are included in the burial dose estimation.

286 (ii) The unweighted arithmetic mean, but with data selected using robust statistics 287 (Tukey, 1977). In this approach extreme outliers are removed prior to calculation of 288 the unweighted mean. Extreme outliers are identified to be those outside the $1.5^{*} \mathrm{IQR}$ 289 (InterQuartile Range), where $\mathrm{IQR}=\mathrm{Q}_{3}-\mathrm{Q}_{1}$ (first quartile $\mathrm{Q}_{1}$ separates the lowest 25\% 290 of the data, third quartile $Q_{3}$ separates the highest $25 \%$ of the data, Tukey, 1977).

291 Unweighted averages and the corresponding standard deviations are then calculated 292 for the resulting distributions.

293 (iii) The Central Age Model, (CAM, Galbraith et al., 1999) which calculates the weighted average including all doses estimates. Most of the dose distributions presented here contains some non-positive dose estimates which prevent the direct use of CAM because of its log-normal assumption. Arnold et al. (2009) described a version of the CAM, CAMuL, in which the log-normal assumption has been replaced by a normal assumption and thus is able to deal with dose distributions containing non-positive dose estimates. However, by using a simple exponential transformation of the data prior to application of the standard CAM, we obtained identical results to those derived from the CAMur. If the individual dose values and their associated uncertainties are termed $D_{i}$ and $S_{i}$, respectively, then the transformed values are and

(iv) The Minimum Age Model (MAM, Galbraith et al., 1999), which assumes that only a proportion of the measured doses belongs to the burial dose distribution and that the remaining dose estimates are part of a log-normal distribution truncated at the burial dose. As with the CAM, the MAM has an underlying log-normal assumption which prevents its application to dose distributions containing non- 
positive dose estimates. Arnold et al. (2009) developed a version of MAM, MAMuL,

310 which is based on the assumption that the dose distributions are normal. However,

311 applying the simple exponential transformation described above also allows the use

312 of the original (and in our experience more stable) MAM scripts. Results derived in

313 this way are termed MAMtr.

314 (v) The Internal-External Consistency Criterion (IEU,Thomsen et al., 2003; 2007) used

315 to identify the lowest normal-dose population; this is presumed to be the population

316 of grains most likely to have been well-bleached at deposition.

317 (vi) The lowest 5\% De values selection suggested by Olley et al., (1998); this approach 318 is included in the decision tree process of Bailey and Arnold, 2006.

\section{Luminescence characteristics}

321 In this section we provide details of the luminescence characteristics of these quartz 322 samples.

\subsection{Decay curves and dose response curves}

324 Figure 2a shows a normalized OSL decay curve from sample T-31 measured using multi-grain ( 30 grains) aliquots; this curve is representative of those from all samples measured here. The natural OSL signal decays to half its initial value in $\sim 0.14 \mathrm{~s}$ and reaches background level in $\sim 0.8 \mathrm{~s}$. Figure $2 \mathrm{a}$ includes a normalized OSL decay curve obtained from calibration quartz, known to be fast component dominated. A comparison of these two curves shows that the OSL signals from the samples investigated here are also fast component dominated. The average multigrain test dose intensity is $700 \pm 120$ counts/Gy integrated over the first $0.64 \mathrm{~s}$. The inset in Figure 2a shows a typical dose response curve from multi-grain aliquots,

333 fitted with a linear function. The corresponding data based on single grain results 
are shown in Figure $2 b$. In this case the dose response curve is fitted using a

335

336

337

338

339

340

341

342

343

344

345

346

347

348

349

350

351

352

353

354

355

356

357

358

359

saturating exponential function but the natural signals generally fall in the linear part of the dose response curves. As is often reported in the literature, the decay shapes of the single grain OSL stimulation curves vary significantly from grain to grain (e.g. Duller, 2008 and references therein). The average test dose intensity from accepted grains is $400 \pm 100$ counts/Gy integrated over the first 0.1 s. No significant differences in terms of luminescence characteristics have been observed among the samples investigated here.

\subsection{Cumulative light sum}

The cumulative light sum (Duller and Murray, 2000) is shown in Figure 3 both for the natural signal and for the signal from the second regeneration dose ( $3 \mathrm{~Gy}$ ) for sample T-26. If all grains contributed equally to the OSL, then the cumulative light sum would be directly proportional to the proportion of grains, with a slope of unity. In our samples $\sim 80 \%$ of the total light is derived from less than $12 \%$ of the grains and $\sim 60 \%$ of the grains do not contribute significantly to the detected signal, providing less than $10 \%$ of the total light sum. A significant proportion of grains with detectable signals is not taken into account in single grain analysis due to the selection criteria; these grains would, of course, contribute to the signal from a multigrain aliquot.

\subsection{Effect of preheat temperature}

To select an appropriate thermal treatment, preheat plateau tests on multi-grain aliquots were measured on samples T-23 and T-39. Based on these measurements, it can be concluded that any preheat temperature below $300^{\circ} \mathrm{C}$ would be appropriate (see Figure 4a).

Thermal transfer was assessed by bleaching 48 previously unused multi-grain aliquots of each of samples T-17, T-26 and T-39 in a daylight simulator (Hönle SOL 2) 
at a distance of $80 \mathrm{~cm}$ from the lamp for two hours prior to measurement. The results

361 from CAMtr average are shown in Figure 4b; each point is the average and standard 362 error of six individual dose estimates. For preheat temperatures less than $240^{\circ} \mathrm{C}$ the $363 \mathrm{CAM}_{\mathrm{tr}}$ average is consistent with zero; even at a preheat temperature of $300^{\circ} \mathrm{C}$ the measured dose is only $\sim 0.25$ Gy. Figure 4c shows the CAMtr doses from similar thermal transfer experiments measured using single grains. A total of 1500 single grains of sample T-30 were measured using preheat temperatures varying between 160 and $260^{\circ} \mathrm{C}$. For this sample the initial bleach was done in the reader using two blue light exposures at room temperature for $40 \mathrm{~s}$ with an intervening pause of $10,000 \mathrm{~s}$. The CAMtr doses for this sample vary between $-2 \pm 8 \mathrm{mGy}$ to $76 \pm 25 \mathrm{mGy}$ for the preheat temperature range considered here. Based on these measurements and the results of the preheat plateau test we chose to employ a preheat temperature of $200^{\circ} \mathrm{C}$ and a cutheat temperature of $180^{\circ} \mathrm{C}$; this combination is commonly used for young samples (e.g. Madsen et al., 2007; Hu et al., 2010).

374 Finally, 2400 grains of sample T-39 were bleached in the daylight simulator for 2 375 hours and measured using a preheat temperature of $200^{\circ} \mathrm{C}$. Of these, 57 grains were accepted, and the resulting dose distribution (see inset to Figure 4c) appears to be symmetric around a weighted mean dose of $16 \pm 7 \mathrm{mGy}$. This weighted dose is consistent with that of sample T-30 measured at a preheat temperature of $200^{\circ} \mathrm{C}(12 \pm$ $10 \mathrm{mGy}, \mathrm{n}=27)$. Combining the results from all the bleached single grains measured at a preheat temperature of $200^{\circ} \mathrm{C}$ gives a weighted average of $15 \pm 6 \mathrm{mGy}(\mathrm{n}=84)$; this corresponds to a residual age of $16 \pm 6$ years (using the average dose rates for these two samples). This value is small, and may not be significantly different from zero. We conclude that thermal transfer is negligible in these samples when using our chosen protocol.

\subsection{Dose recovery}


As a final test of the luminescence characteristics and our measurement protocol, we have carried out dose recovery tests on both multi-grain aliquots (samples T-17, T-30 and T-39) and single grains (sample T-39) using a preheat temperature of $200^{\circ} \mathrm{C}$ and a cutheat of $180^{\circ} \mathrm{C}$ to investigate whether a known dose given prior to any thermal treatment can be recovered accurately. In these experiments all samples were bleached for two hours in the daylight simulator prior to dosing.

392 In one set of experiments, seven bleached multi-grain aliquots from each of the three samples were given a beta dose (in the reader) of 2 Gy. The average dose recovery ratios obtained were $0.91 \pm 0.07,0.99 \pm 0.04$ and $0.90 \pm 0.02(n=7)$ for samples T-17, T30 and T-39, respectively. Combining the results from the three samples gives an average weighted dose recovery ratio of $0.93 \pm 0.03(\mathrm{n}=21)$ and an over-dispersion (OD) of $4 \pm 4 \%$, indistinguishable from zero.

In a different dose recovery experiment, a portion of the bleached sample T-39 was given a gamma dose of 2 Gy prior to multi-grain measurement. The dose recovery ratio for this sample was $1.07 \pm 0.03(n=48)$ with an OD of $7 \pm 4 \%$. The overdispersion derived from this experiment is consistent with that derived from the beta dose recovery experiment.

In a third experiment, 1,000 single grains of the bleached portion of sample T-39 were measured after being given a beta dose of $2 \mathrm{~Gy}$ in the reader. The dose recovery ratio was $0.98 \pm 0.09(n=18)$ with an OD of $16 \pm 8 \%$.

406 Finally, 3200 grains of the gamma irradiated portion of sample T-39 gave a weighted dose recovery ratio of $0.98 \pm 0.04(n=66)$ with an OD value of $22 \pm 5 \%$ (after taking into account beta source inhomogeneity, see below).

409 From the gamma dose recovery experiments it would appear that assigning 410 uncertainties based on counting statistics and curve fitting errors alone is insufficient 411 to describe the observed variability in an sample known to have been uniformly 412 irradiated. A similar conclusion was reached previously by Thomsen et al. (2005; 16 
2007; 2012), Reimann et al. (2012), and Sim et al. (2012). For all multi-grain and single

414 grain measurements we add in quadrature an additional uncertainty (additional to 415 that calculated from counting statistics and curve fitting errors) of $7 \%$ and $22 \%$, respectively. This additional uncertainty is added to account for the variability in measured dose distributions arising from additional intrinsic factors; we regard this as the minimum uncertainties with which any dose can be measured using a single aliquot or single grain. If extrinsic sources of variability (e.g. small scale beta dose rate heterogeneity) contribute significantly to the spread in the well-bleached part of the dose distributions, our additional intrinsic uncertainty $(7 \%$ for small aliquots and $22 \%$ for single grains) is likely to underestimate the actual variability in a wellbleached dose distribution.

\subsection{Effect of beta source inhomogeneity}

425

426

427

It has been reported (Spooner et al., 2000; Thomsen et al., 2005; Ballarini et al., 2006; Lapp et al., 2012) that the laboratory dose rate from the in-built beta source can be inhomogeneous across the sample area due to the position of the radioactive material on the active surface of the beta source. This effect is usually not important when measuring multi-grain aliquots but can contribute significantly to the observed variability in single grain dose distributions.

Two different beta sources were used for the single grain measurements. One of them, source ID155, was manufactured before 2000 and is thus expected to have a relatively uniform distribution of radioactive material while ID195 was manufactured in 2006 and is thus expected to have a wider spatial variation (Lapp et al, 2012). Mapping the beta source following the approach of Lapp et al. (2012) showed that the effective dose rate varied spatially by up to $5 \%$ and $13 \%$ for the sources ID155 and ID195, respectively. Lapp et al. (2012) have developed software that makes it possible to correct for this dose rate inhomogeneity automatically using this dose-rate map. This source inhomogeneity contributes to the intrinsic over- 
dispersion discussed in the previous section; the size of this contribution can be

441 determined by analysing a bleached and gamma dosed sample with and without 442 correction for inhomogeneity. The observed OD is $29 \pm 6 \%$ without correction for 443 inhomogeneity and this decreases to $22 \pm 5 \%$ when the correction is employed, 444 suggesting that beta source homogeneity contributes $19 \pm 8 \%$ to the total observed 445 OD of $29 \%$.

\section{$446 \quad 5 . \quad$ Natural dose distributions}

\section{$447 \quad$ 5.1. Single grain results}

448 Between 3,000 and 5,000 grains from each sample were measured, resulting in 80-100 449 dose estimates per sample passing the rejection criteria described in section 3.3. 450 Natural dose distributions showing the OSL response from the natural test dose as a function of the measured dose are shown in Figure 5. All dose distributions appear to be positively skewed with a minimum dose edge possibly indicating the presence of incomplete bleaching. Simple visual inspection of the dose distributions suggests that more than $60 \%$ of all grains may belong to single dose distributions centred at the low end of the observed values.

\subsubsection{Effect of the chosen background summation limits}

457 As discussed in section 3.3, a late background (LBG) subtraction has been used to 458 obtain the net OSL signal from single grains; this is in contrast to the use of an early background, EBG, usually expected to minimise any effects of slower components 460 on the net signal (Cunningham and Wallinga, 2010). A comparison of the results

461 using EBG and LBG has been undertaken using single grains from sample T-31. 462 With EBG, 2.2\% of the measured grains were accepted, giving a CAMtr burial dose 463 and over-dispersion of $1.5 \pm 0.6 \mathrm{~Gy}$ and $300 \pm 50 \%$. Estimating the minimum burial 464 dose using IEU gives $0.152 \pm 0.014 \mathrm{~Gy}(\mathrm{n}=49)$. The use of LBG results in the 465 acceptance of $3.1 \%$ of the grains, giving a CAMtr burial dose of $1.6 \pm 0.5 \mathrm{~Gy}$ and over- 
dispersion of $280 \pm 30 \%$. Using IEU on this dose distribution gives a minimum

467 burial dose of $0.134 \pm 0.012 \mathrm{~Gy}(\mathrm{n}=54)$. Thus there does not appear to be any

468 significant difference between the estimated burial doses using either EBG or LBG 469 for single grains (consistent with the results reported by Reimann et al., 2012). The 470 over-dispersion of the dose distributions obtained using both EBG and LBG has been 471 calculated for all eight samples. Again no significant differences in the ODs are 472 observed for any one sample, although there is a slight systematic tendency for 473 lower OD values when using LBG. More importantly, EBG results in a significant 474 reduction $(\sim 30 \%)$ in the number of accepted grains. Thus for these samples, it would 475 appear that using LBG gives rise to a larger data set with no detectable cost in data 476 quality.

\subsubsection{Single-grain burial dose estimates}

478 As a first approach to burial dose estimation we calculate a simple unweighted average dose including all dose points. The results are given in Table 2 and shown in Figure 6a. Such a simple approach leads to an average over-estimation of the expected dose of $\sim 1$ Gy $(n=8)$, consistent with the range of values given in many reports of residual doses in modern water-lain deposits (see recent summary in Murray et al., 2012).

In an attempt to improve this simple average, we applied "robust statistics" where extreme outliers are eliminated following the $1.5^{*} \mathrm{IQR}$ criterion described in section 3.4; because of the shape of the dose distributions of these samples, all outliers identified following this criterion belong to the higher dose region of the distributions; no low dose values were rejected. The average overestimate compared to expected doses is reduced from $\sim 1$ Gy to $\sim 0.15$ Gy. Samples T-36, T-23 and T-17 now give results consistent with the expected doses within two standard deviations.

491 The remaining samples overestimate ( 0.3 Gy) the expected doses, with the largest 492 overestimate occurring for the two youngest samples (T-39 and T-37). Thus, 
although the interquartile range criterion is not based on any physical process model, it provides a significantly better-constrained estimate of the upper dose limit to the burial dose estimate than the simple average.

496 The next step was to derive weighted mean equivalent doses using the CAM model

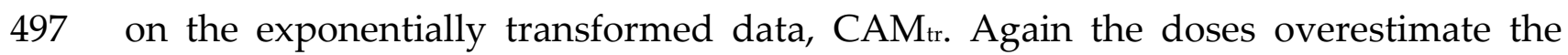
expected values, by $\sim 0.9$ Gy on average. Clearly, the dose overestimates do not arise simply because of large, poorly known dose values.

500 As these samples are expected to be affected by incomplete bleaching because of the nature of the deposition process and the shape of the measured dose distribution, we expected to have to apply minimum age models to determine the true burial dose. In the following we apply the MAM model using exponentially transformed data, $\mathrm{MAM}_{\mathrm{tr}}$ ( (see section 3.4) because of the presence of non-positive dose estimates in all our dose distributions (except that from sample T-17, the oldest sample). Prior to the application of the MAMtr model an additional uncertainty of $22 \%$ has been added to the uncertainty of all dose estimates calculated from counting statistics and curve fitting errors (see section 4.4) to account for intrinsic sources of uncertainty including instrument reproducibility. This additional uncertainty of $22 \%$ was added as a percentage of the individual dose estimates. For both minimum age models, MAMtr and IEU, all data sets have been corrected for beta source inhomogeneity. The minimum doses are given in Table 2 and shown in Figure 6a. Applying the MAMtr to the dose distributions we obtain agreement with the expected doses (within two standard errors) for four of the samples (T-36, T-26, T-23 and T-17) which have measured to expected dose ratios of $1.56 \pm 0.29,1.28 \pm 0.15,1.08 \pm 0.10$ and $1.00 \pm 0.11$. There is a clear trend of increasing overestimation as a function of decreasing expected dose - the best agreement is obtained for samples older than 350 years.

518 The MAMtr burial dose estimates for the remaining samples are in poor agreement with the independent age control. 
To test the IEU approach, we first fitted a straight line between the absolute OD as a

521 function of the estimated dose obtained for the 2 Gy gamma dose recovery

522 experiment and that obtained for the distribution of the thermal transfer experiment

523 (0 Gy dose, see Thomsen et al., 2007). The relation obtained for OD as a function of

524 dose is given by $\mathrm{OD}=0.2073 \cdot \mathrm{D}+0.0183$, where $\mathrm{D}$ is the given dose. This $\mathrm{OD}$ was

525 added in quadrature to all single grain data before iteratively applying the IEU

526 model as described by Thomsen et al. (2007) to determine the IEU burial dose. The

527 resulting IEU burial doses are in good agreement with all predicted doses; the

528 estimates are within one standard error for four of the eight samples (T-37, T-36, T-31

529 and T-17) and within two standard errors for the other four.

530 Finally we investigated how sensitive our estimated MAMtr and IEU burial doses for samples T-39 and T-31 are to the size of the assigned additional uncertainty which we varied from $5 \%$ to $50 \%$. The results are shown in Figure $7 \mathrm{a}$ and $7 \mathrm{c}$, where it can

533 be seen that the MAM $_{\text {tr }}$ overestimates the expected doses even for the lowest additional intrinsic uncertainty tested (5\%); we are, of course, confident that the intrinsic OD must be considerably greater than $5 \%$ as the instrument reproducibility alone has been assessed to be $\sim 6 \%$ (e.g. Thomsen et al., 2005). In contrast, the IEU results are relatively insensitive to added uncertainty, giving doses within two standard deviations of the expected values for additional uncertainties in the range 5 to $40 \%$ for single grain measurements.

540 Burial doses estimated using the different approaches are summarized in Table 2,

541 together with the number of grains, $n$, included in each case. For robust statistics $n$ is

542 the number of grains remaining after removing outliers. For MAMtr and IEU, $n$ is the 543 number of grains identified as belonging to the well bleached part of each dose

544 distribution. The estimated doses plotted against the expected values are shown in 545 Figure 6a.

\section{5.2. Multi-grain results}


547 Between 80 and 100 multi-grain aliquots ( 30 grains each) were measured for each

548 sample. Laboratory gamma dose recovery tests gave an OD of $7 \pm 4 \%$ (n $=48$; see 549 section 4.4) and so we add an additional uncertainty of $7 \%$ to individual dose 550 estimates to account for intrinsic sources of variability. Observed natural dose 551 distributions and the corresponding expected doses are shown in Figure 8. All 552 distributions appear to be positively skewed and include a number of dose values 553 significantly higher than those expected. Sample T-37 is unusual, in that even the 554 leading dose edge seems to be off-set to higher doses compared to the expected dose. This observation is consistent with the single grain IEU analysis (see Table 2) which concluded that T-37 was the most poorly bleached sample with only $\sim 20 \%$ of the grains identified to be well-bleached (see section 5.1.2).

The over-dispersion values for the natural samples are very similar to those determined for the single grain dose distributions (see Table 2). The simple averages, as well as the CAMtr, overestimate the expected dose by $3 \mathrm{~Gy}$ on average. Although it can usually be argued that it is inappropriate to apply statistical age models to multi-grain data sets, in this case, given the conclusion from the cumulative light sum, we analyse the multi-grain aliquot data set in the same manner as the single grain data.

565 The ratio between the MAMtr multi-grain burial dose and the expected dose is only consistent with unity (within two standard errors) for the oldest sample (T-17), which has a ratio of $0.93 \pm 0.26$. The remaining seven samples are in poor agreement with the independent age control; the measured to expected dose ratios vary between $1.24 \pm 0.09$ and $7.9 \pm 1.0$. The MAMtr overestimation tends to increase for decreasing expected dose. If we apply the IEU approach to the multi-grain dose distributions, six of the eight samples have measured to expected dose ratios consistent with unity within two standard errors. Samples T-37 and T-30 significantly overestimate the expected dose; the ratios are $3.9 \pm 0.5$ and $1.5 \pm 0.1$ respectively. 
576 For the extreme case of T-37 where the single grain analysis showed that $\sim 80 \%$ of the

577

578

579

580

581

582

583

584

585

586

587

588

589

590

591

592

593

594

595

596

597

598

599

grains are poorly bleached, the presence of a large number of grains with significant residual doses prevents accurate analysis by any of the statistical analyses used here.

Following the same procedure applied to single grains (see section 5.1.2), we tested the dependence of $\mathrm{D}_{\mathrm{e}}$ on additional uncertainty using samples T-39 and T-31. Figure $7 \mathrm{~b}$ and $7 \mathrm{~d}$ shows that any additional uncertainty greater than $\sim 7 \%$ results in a significant overestimate of the expected dose for both MAM $\mathrm{tr}_{\mathrm{r}}$ and IEU..

\section{Discussion}

The aim of this study is to explore the most suitable methods for burial dose estimation for flash-flood deposits, and such an investigation requires a set of known age deposits. We consider our age control - historical records and radiocarbon for the oldest sample T-17 ( 1000 years) - sufficiently reliable to allow us to assign calendar ages to individual flood events (Benito et al., 2010) and so derive expected equivalent doses.

Single grain dose distributions have been measured from each of our 8 samples, and these distributions analysed using various approaches. Unsurprisingly, those approaches which include all dose points in the estimation (simple average and $\mathrm{CAM}_{\mathrm{tr}}$ ) significantly overestimate the expected age, but only by about 1000 years, corresponding to a mean residual dose at deposition of $<1 \mathrm{~Gy}$. Thus, despite the fact that our sediments were deposited by short-lived flash floods, the residual doses are comparable with other reports of residuals in modern river sediments, including non-flood deposits. We deduce that most of the light exposure of our sediment samples must have taken place before the final transport by the flash flood which finally deposited the sediment. It is also important to note that although for these 
very young samples a dose overestimation of $\sim 1$ Gy is unacceptable, such an overestimation would be trivial for older samples (e.g. $>10 \mathrm{ka}$ ).

602 The observation that the estimates from robust statistics (which only rejected the 603 upper $15 \%$ of grains, on average) are close to the expected ages for three of the 604 samples (T-36, T-23 and T-17) suggests that only a small fraction of the grains were 605 actually incompletely bleached. This is also consistent with the results from the IEU 606 minimum dose approach which identifies these three samples to be the ones with 607 large well-bleached populations, that is $70 \%(n=78), 77 \%(n=62)$ and $75 \%(n=59)$ of 608 the grains, respectively. This suggests that if samples containing a moderate percentage of incompletely bleached grains (perhaps $<30 \%$ ) can be identified a priori, a simple non-subjective elimination of high-dose outliers would provide accurate ages; this approach would avoid the need for assumptions concerning OD, and the use of more complex statistical analysis.

613 The remaining five samples appear to include a higher proportion of incompletely 614 bleached grains in their dose distributions, and minimum age models (IEU and 615 MAM) were necessary to obtain accurate results. All single grain burial dose 616 estimates from the IEU model are in agreement with the doses predicted by the 617 historical record, radiocarbon (and incidentally are completely bracketed by the ${ }^{14} \mathrm{C}$ 618 modelled ages of Thorndycraft et al., 2012).

619 The dose distributions from these young samples contain non-positive dose 620 estimates which prevented the direct use of MAM due to its log-normal assumption. 621 However, this problem is easily overcome applying an exponential transformation to 622 the data and then using the original MAM scripts (this analysis using transformed 623 data is termed MAMtr). To confirm that ages estimated with MAMtr can be directly 624 compared with any other published results in which estimates were obtained using MAMur, burial doses for all samples have been calculated with both variations of the 
original MAM (MAMur and MAMtr) with identical results. In our experience MAMtr is less sensitive to model starting parameters and is more robust in use.

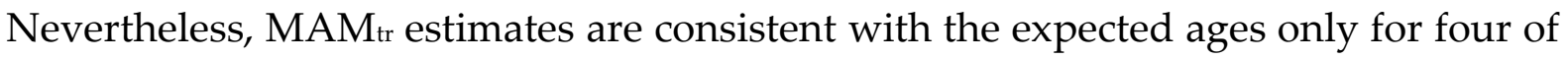
the eight samples: the three oldest samples, T-26, T-23 and T-17 (>350 years) and sample T-36 (expected from independent age control to be 119 years and have a corresponding $\mathrm{D}_{\mathrm{e}}$ of $\left.0.109 \pm 0.006 \mathrm{~Gy}\right)$. This inaccuracy of MAMtr burial dose estimates might be expected to have arisen because the assigned uncertainties (derived from gamma dose recovery experiments) are larger than those actually occurring in nature. However investigation of the sensitivity of MAMtr burial doses to the size of the assigned uncertainty shows that the MAMtr model overestimates the expected doses even for the lowest additional intrinsic OD tested (5\%), (see Figure 7); we are confident that the intrinsic OD must be considerably greater than this as the instrument reproducibility alone is $\sim 6 \%$ per dose estimate (Thomsen et al., 2005).

640 It is also interesting to test the performance of the decision tree protocol of Bailey and Arnold (2006) using these data. These authors suggest a decision tree to identify the most appropriate statistical model to apply to a given dose distribution. For our eight samples, this decision tree predicts that the true burial dose is best estimated

644 using the lowest $5 \%$ of the dose estimates for all dose distributions except for the oldest sample (T-17) for which the predicted model is MAM-4. The MAM-4 dose estimated for T-17 is $1.03 \pm 0.05 \mathrm{~Gy}$, indistinguishable from the MAMtr (3 parameters) result (see Table 2) and consistent with the independent age control. However, for 648 the seven youngest samples ( $\leq 450$ years old) using the lowest $5 \%$ of the dose 649 distribution (after rejection of the negative dose values) results in significant underestimations of the burial doses, of about 80 to $85 \%$.

651 Despite the expectation that these samples were incompletely bleached, burial doses 652 were also estimated using small multi-grain ( 30 grains) aliquots. The 
overestimation found when applying simple average and CAMtr to these data

654

655

656

657

658

659

660

661

662

663

664

665

666

667

668

669

670

671

672

673

674

675

676

677

678

679

confirms that if all results are included in the burial dose estimates, then there is a large contribution from incompletely bleached grains giving an average overestimate of $<3 \mathrm{~Gy}$ (corresponding to 3000 years). According to the cumulative light sum obtained from single-grain measurements (section 4.2) the total light from a multi-grain aliquot containing $\sim 30$ grains must be dominated by the light from $\sim 3.5$ grains. Thus at least some of the aliquots can be expected to behave like single grains. In addition IEU results from single grains indicate that $38-77 \%$ of the grains from the samples (except T-37) are well bleached. Thus, it is to be anticipated that the signal from a number of multi-grain aliquots will only be derived from well bleached grains. Both minimum age models (MAMtr and IEU) were used to estimate the burial dose from multi-grain dose distributions. The MAMtr resulted in ages consistent with the known ages only for the two oldest samples, whereas the IEU derived consistent estimates for six of the eight samples. Only the ages of the two youngest samples (T-39 and T-37, 40 and 70 years old, respectively) were overestimated, by approximately 30 and 10 years.

Over the last few years, single grains have been increasingly been used almost routinely for fluvial deposits, despite the measurement and analysis time involved (e.g. Thomas et al., 2005; Arnold et al., 2007; Thomsen et al., 2007). However from the results of this study we conclude that accurate age can be obtained using small ( 30 grains) multi-grain aliquots in combination with the IEU approach. In our eight samples this would result in an average offset in dose of $43 \pm 20 \mathrm{mGy}(\mathrm{n}=8, \sim 40$ years). This suggests that it may not be necessary to resort to single grain analysis of fluvial deposits if deposition ages are much older than a few decades.

Nevertheless, if the IEU model (but not MAM ${ }_{\text {tr }}$ ) is applied to single grain data even this small offset is removed (average offset is $-8 \pm 8 \mathrm{mGy}, \mathrm{n}=8$ ); this approach gives the most accurate ages overall, including for the youngest samples ( $<100$ years old). 
These preferred ages (i.e. obtained using the IEU approach) and the ratio of these ages and those from independent age control are summarized in Table 3.

\section{7. Conclusion}

683 A number of studies have addressed the OSL dating of individual flood layers, most 684 of them from large fluvial catchments (Stokes et al., 2001, Grodek et al., submitted). In small basins $\left(<500 \mathrm{~km}^{2}\right)$ one might expect a large effect from incomplete bleaching in sediments transported by flash-floods over short distances. At the Estrecho site on

687 Guadalentín River slack-water deposits are emplaced by such short-lived flash floods. We have applied a variety of statistical tools in the analysis of single-grain dose distributions from these samples. Unsurprisingly, those models which use all the doses in a distribution (unweighted average and CAM) overestimate the known age. Nevertheless the implied residual doses are small, and are comparable to, or smaller than, reported residuals in a variety of modern river sediments, including non-flood deposits. We conclude that our samples must have been bleached mainly before the final transport by the flash-flood which deposited the sediment. Although small, the residual doses remaining at deposition are significant compared to the doses absorbed since deposition by these known-age young samples, but even an approach which simply rejects outliers in the dose distribution (so-called 'robust statistics') is able to provide accurate age estimates in several samples. Of the two models (IEU and MAMtr) which set out to identify the well-bleached part of the dose distribution, both perform well on older samples, but the IEU is clearly the more accurate for samples containing doses $<0.4 \mathrm{~Gy}$ ( $<450$ years). Interestingly, acceptably accurate results can be obtained for all but the youngest two samples using the IEU on dose estimates from small multi-grain aliquots, suggesting that the more timeconsuming and labour intensive single-grain analyses are not always necessary when analysing incompletely bleached sediments. 
706 Our data show that quartz OSL dating can be used to derive accurate age estimates

707 covering the last few decades to hundreds of years using sediment deposited during

708 flash-floods in small catchments. This opens up the exciting possibility of generating 709 time series of flood discharge at sites without any monitoring or other historical 710 record.

\section{8. Acknowledgments}

712 This study was funded by the Spanish Ministry of Economy and Competitiveness 713 through the research projects FLOOD-MED (ref. CGL2008-06474-C02-01), and 714 CLARIES (ref. CGL2011-29176), and by the CSIC PIE Intramural Project (ref. 715 200430E595).

\section{$716 \quad 9 . \quad$ References}

717 Arnold, L.J., Bailey, R.M., Tucker, G.E., 2007. Statistical treatment of fluvial dose 718 distributions from southern Colorado arroyo deposits. Quaternary Geochronology 2, $7191-4,162-167$.

720 Arnold, L.J., Roberts, R.G., Galbraith, R.F., DeLong, S.B., 2009. A revised burial dose

721 estimation procedure for optical dating of young and modern-age sediments. 722 Quaternary Geochronology 4, 306-325.

723 Bailey, R.M., Arnold, L.J., 2006. Statistical modelling of single grain quartz De 724 distributions and an assessment of procedures for estimating burial dose. 725 Quaternary Science Reviews 25, 2475-2502

726 Baker, V.R., 2008. Paleoflood hydrology: Origin, progress, prospects. 727 Geomorphology 101, 1-2, 1-13.

728 Ballarini, M., Wintle, A.G., Walinga, J., 2006. The spatial variation of dose rate beta as 729 measured using single grains. Ancient TL 24, 1-8. 
730 Barriendos, M. and Coeur, D., 2004. Flood data reconstruction in historical times 731 from non-instrumental sources in Spain and France. Systematic, palaeoflood and 732 historical data for the improvement of flood risk estimation (G. Benito \& V.R. 733 Thorndycraft, eds.). Methodological Guidelines. European Commission. 29-42.

734 Benito, G., Lang, M., Barriendos, M., Llasat, M.C., Francés, F., Ouarda, T., 735 Thorndycraft, V., Enzel, Y., Bardossy, A., Coeur, D., Bobée, B., 2004. Use of 736 systematic, palaeoflood and historical data for the improvement of flood risk 737 estimation. Review of scientific methods. Natural Hazards 31, 623-643.

738 Benito G. and Thorndycraft V.R., 2005. Palaeoflood hydrology and its role in applied 739 hydrological sciences. Journal of Hydrology, 313 (1-2), 3-15.

740 Benito, G., Rico M., Sánchez-Moya Y. Sopeña, Thorndycraft V. R \& Barriendos, M., 741 2010. The impact of late Holocene climatic variability and land use change on the 742 flood hydrology of the Guadalentín River, southeast Spain. Global and Planetary 743 Change 70, 53-63.

744 Benito, G. and O'Connor, J.E. ,2012. Quantitative Paleoflood Hydrology. In: Wohl, 745 E.E., Treatease in Geomorphology. Elsevier, in press.

746 Bøtter-Jensen, L., Bulur, E., Duller, G.A.T., Murray, A.S., 2000. Advances in 747 luminescence instrument systems. Radiation Measurements 32, 5-6, 523-528.

748 Bøtter-Jensen, L., Thomsen, K.J., Jain, M., 2010. Review of optically stimulated 749 luminescence (OSL) instrumental developments for retrospective dosimetry. 750 Radiation Measurements 45, 3-6, 253-257.

751 Colls A.E., Stokes S., Blum M.D. and Straffin E., 2001. Age limits on the Late 752 Quaternary evolution of the upper Loire River. Quaternary Science Reviews 20: 743753750. 
754 Cunningham, A., Wallinga, J., 2010. Selection of integration time intervals for quartz 755 OSLdecay curves. Quaternary Geochronology 5, 657-666.

756 Duller, G.A.T., Bøtter-Jensen, L., Murray, A.S., Truscott, A.J. 1999. Single grain laser 757 luminescence (SGLL) measurements using a novel automated reader. Nuclear 758 Instruments and Methods in Physics Research Section B: Beam Interactions with 759 Materials and Atoms 155, 4, 506-514.

760 Duller, G.A.T. and Murray, A.S, 2000. Luminescence dating of sediments using 761 individual mineral grains. Geologos 5, 87-106.

762 Duller, G.A.T., 2007. Assessing the error on equivalent dose estimates derived from 763 single aliquot regenerative dose measurements. Ancient TL 25, 1.

764 Duller, G. A. T. 2008. Single-grain optical dating of Quaternary sediments: why 765 aliquot size matters in luminescence dating. Boreas, 37, 589-612

766 Fuchs, M., Straub, J., Zöller, L., 2005. Residual luminescence signals of recent river 767 flood sediments: a comparison between quartz and feldspar of fine- and coarse-grain 768 sediments. Ancient TL 23, 1.

769 Galbraith, R.F., Roberts, R.G., Laslett, G.M., Yoshida, H., Olley, J.M., 1999. Optical 770 dating of single and multiple grains of quartz from Jinmium rock shelter, Northern 771 Australia: Part 1, experimental design and statistical models. Archaeometry 41, 339772364.

773 Galbraith, R.F., 2005. Statistics for Fission Track Analysis. Chapman and Hall/CRC 774 Press, Boca Raton, FL.

775 Grodek, T., Benito, G., Botero, B.A., Jacoby, Y., Porat, N., Haviv, I., Cloete, G., Enzel, 776 Y. The last millennium largest floods along the hyperarid Kuiseb River Canyon, 777 Namibia. Journal of Quaternary Science, Submitted. 
778 Hu, G., Zhang, J.F., Qiu, W.L., Zhou, L.P., 2010. Residual OSL signals in modern 779 fluvial sediments from the Yellow River (HuangHe) and the implications for dating 780 young sediments. Quaternary Geochronology 5, 2-3, 187-193.

781 Kochel, R.C. and Baker, V.R., 1982. Paleoflood hydrology. Science 215, 353-361.

782 Kromer, B. and Becker, B. 1993. German oak and pine ${ }^{14} \mathrm{C}$ calibration, $7200-9439$ BC. 783 Radiocarbon 35, 1, 125-135.

784 Lapp, T., Jain, M., Thomsen, K.J., Murray, A.S., Buylaert, J.P., 2012. New 785 luminescence measurement facilities in retrospective dosimetry. Radiation 786 Measurements 47, 9, 803-808.

787 Linick, T. W., Long, A., Damon, P. E. and Ferguson, C. W., 1986. High-precision 788 radiocarbon dating of bristlecone pine from 6554 to 5350 BC. In Stuiver, M. and Kra, 789 R. S., eds., Proceedings of the $12^{\text {th }}$ International ${ }^{14} \mathrm{C}$ Conference. Radiocarbon $28(2 \mathrm{~B})$ : $790 \quad 943-953$.

791 Machado, M.J., Benito, G., Barriendos, M., Rodrigo, F.S., 2011. 500 years of rainfall 792 variability and extreme hydrological events in Southeastern Spain drylands. Journal 793 of Arid Environments 75, 1244-1253.

794 Madsen, A.T., Murray, A.S., Andersen, T.J., Pejrup, M., 2007. Optical dating of young 795 tidal sediments in the Danish Wadden Sea. Quaternary Geochronology 2, 1-4, 89-94.

796 Madsen, A.T., Murray, A. S., 2009. Optically stimulated luminescence dationg of 797 young sediments: A review. Geomorphology 109, 3-16.

798 Murray, A.S., Marten, R., Johnston, A., Martin, P., 1987. Journal of Radioanalytical 799 and Nuclear Chemistry, Articles 115, 2, 263-288.

800 Murray, A.S. and Wintle, A.G., 2000. Luminescence dating of quartz using an 801 improved single-aliquot regenerative-dose protocol. Radiation Measurements 32, 5780273. 
Murray, A.S. and Wintle, A.G., 2003. The single aliquot regenerative dose protocol: potential for improvements in reliability. Radiation Measurements 37, 377-381.

805

Murray, A.S. and Olley, J.M., 2002. Precision and accuracy in the optically stimulated

806 luminescence dating of sedimentary quartz: a status review. Geochronometria 21, 180716.

808 Murray, A.S., Thomsen, K.J., Masuda, N., Buylaert, J.P., Jain, M., 2012. Identifying 809 well-bleached quartz using the different bleaching rates of quartz and feldspar 810 luminescence signals. Radiation Measurements 47, 9, 688-695.

811 Olley, J. M., Murray, A. S. \& Roberts, R. G. 1996. The effects of disequilibria in the 812 uranium and thorium decay chains on the burial dose rates in fluvial sediments.

813 Quaternary Science Reviews 15, 751-760.

814 Olley J.M., Caitcheon G.G. and Murray A.S., 1998. The distribution of apparent dose 815 as determined by optically stimulated luminescence in small aliquots of fluvial 816 quartz: implications for dating young sediments. Quaternary Science Reviews 17, $817 \quad 1033-1040$.

818 Prescott, J.R., Hutton, J.T., 1994. Cosmic ray contributions to dose rates for 819 luminescence and ESR: large depths and long-term time variations. Radiation 820 Measurements 23, 497-500.

821 Reimann, T., Lindhorst, S., Thomsen, K.J., Murray, A.S., Frechen, M., 2012. OSL 822 dating of mixed coastal sediment (Sylt, German Bight, North Sea). Quaternary 823 Geochronology 11, 52-67.

824 Rhodes, E., 2000. Observations of thermal transfer OSL signals in glacigenic quartz. 825 Radiation Measurements 32, 5-6, 595-602.

826 Rhodes, E., 2007. Quartz single grain OSL sensitivity distributions: implications for 827 multiple grain single aliquot dating. Geochronometria 26, 19-29. 
828 Rittenour, T.M., 2008. Luminescence dating of fluvial deposits: Applications to 829 geomorphic, palaeoseismic and archaeological research. Boreas 37, 613-635.

830 Sim, A.K., Thomsen, K.J., Murray, A.S., Jacobsen, G., Drysdale, R. and Erskine, W. 831 (submitted in 2012). Dating recent floodplain sediments in the Hawkesbury-nepean 832 river system using single grain quartz OSL. Submitted to Boreas.

833 Spooner, N.A., Allsop, A., 2000. The spatial variation of dose rate from ${ }^{90} \mathrm{Sr} /{ }^{90} \mathrm{Y}$ beta 834 sources for use in luminescence dating. Radiation Measurements 32, 97-102.

835 Stokes, S., Bray, H.E., Blum, M.D., 2001. Optical resetting in large drainage basins: 836 tests of zeroing assumptions using single-aliquot procedures. Quaternary Science 837 Reviews 20, 879-885.

838 Stuiver and Pearson, 1993. High-precision calibration of the radiocarbon time scale, 839 AD 1950-500 BC and 2500-6000 BC. Radiocarbon, 35, 1.

840 Thomas, P.J., Jain, M., Juyal, N., Singhvi, A.K., 2005. Comparison of single-grain and 841 small-aliquot OSL dose estimates in years old river sediments from South India, 842 Radiation Measurements 39, 5, 457-469.

843 Thomsen, K.J., Jain, M., Bøtter-Jensen, L., Murray, A.S., Jungner, H., 2003. Variation 844 with depth of dose distributions in single grains of quartz extracted from an 845 irridatiated concrete block. Radiation Measurements 37, 315-321.

846 Thomsen, K.J., Murray, A.S., Bøtter-Jensen, L., 2005. Sources of variability in OSL 847 dose measurements using single grains of quartz. Radiation Measurements 39, 47-61.

848 Thomsen, K.J., Murray, A.S., Bøtter-Jensen, L., Kinahan, J., 2007. Determination of 849 burial dose in incompletely bleached fluvial samples using single grains of quartz. 850 Radiation Measurements 42, 3, 370-379. 
851 Thomsen, K.J., Murray, A.S. and Jain, M., 2012. The dose dependency of the over852 dispersion of quartz OSL single grain dose distributions. Radiation Measurements 47 $853(9), 732-739$.

854 Thorndycraft, V.R., Benito, G., Sánchez-Moya, Y. and Sopeña, A., 2012. Bayesian age 855 modelling applied to palaeoflood geochronologies and the investigation of Holocene 856 flood magnitude and frequency The Holocene, 22, 1, 13-22.

857 Truelsen, J.L. and Wallinga, J, 2003. Zeroing of the OSL signal as a function of grain 858 size: investigating bleaching and thermal transfer for a young fluvial sample. 859 Geochronometria 22, 1-8.

860 Tukey, J.W, 1977. Exploratory Data Analysis. Reading, Mass.: Addison Wesley.

861 Wallinga, J., 2002. Optically stimulated luminescence dating of fluvial deposits: a 862 review. Boreas 31, 303-322.

863 Wintle, A.G. and Murray, A.S., 2006. A review of quartz optically stimulated

864 luminescence characteristics and their relevance in single-aliquot regeneration 865 dating protocols. Radiation Measurements 41, 4, 369-391.

866

867

868 


\section{ESTRECHO SITE}
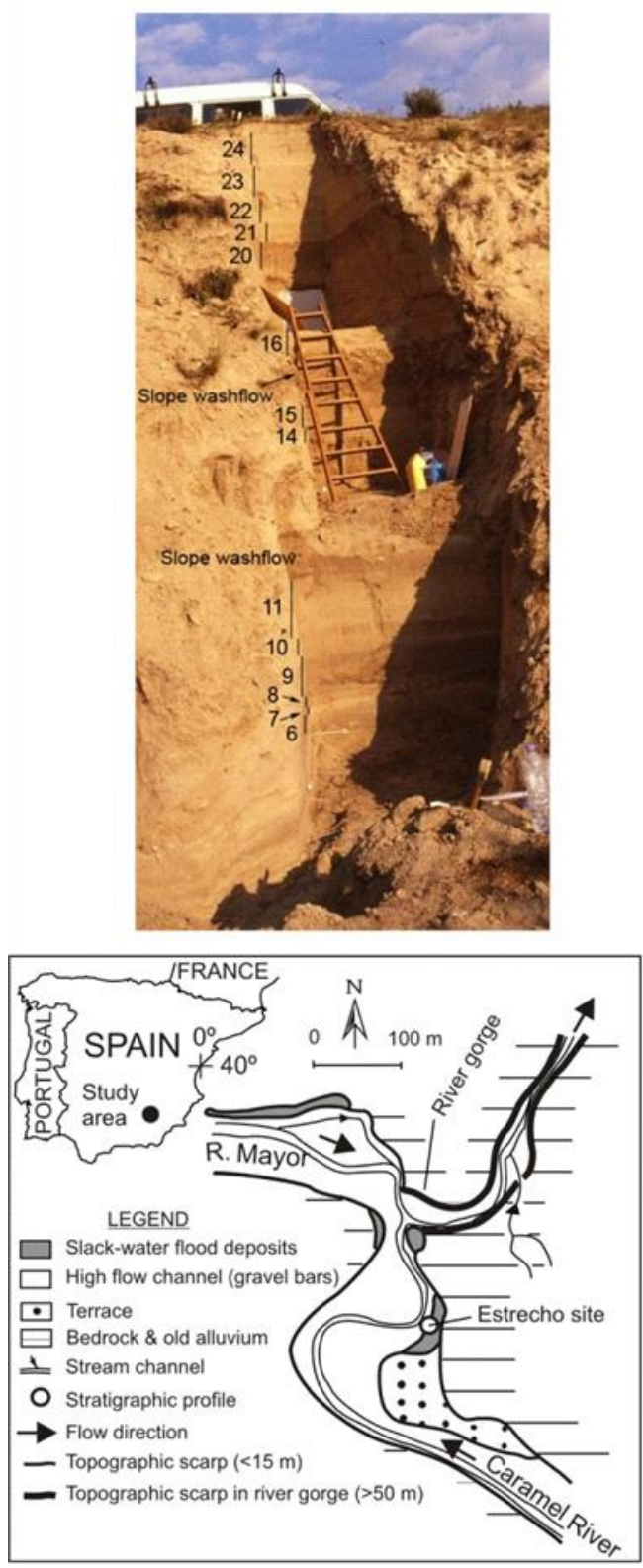

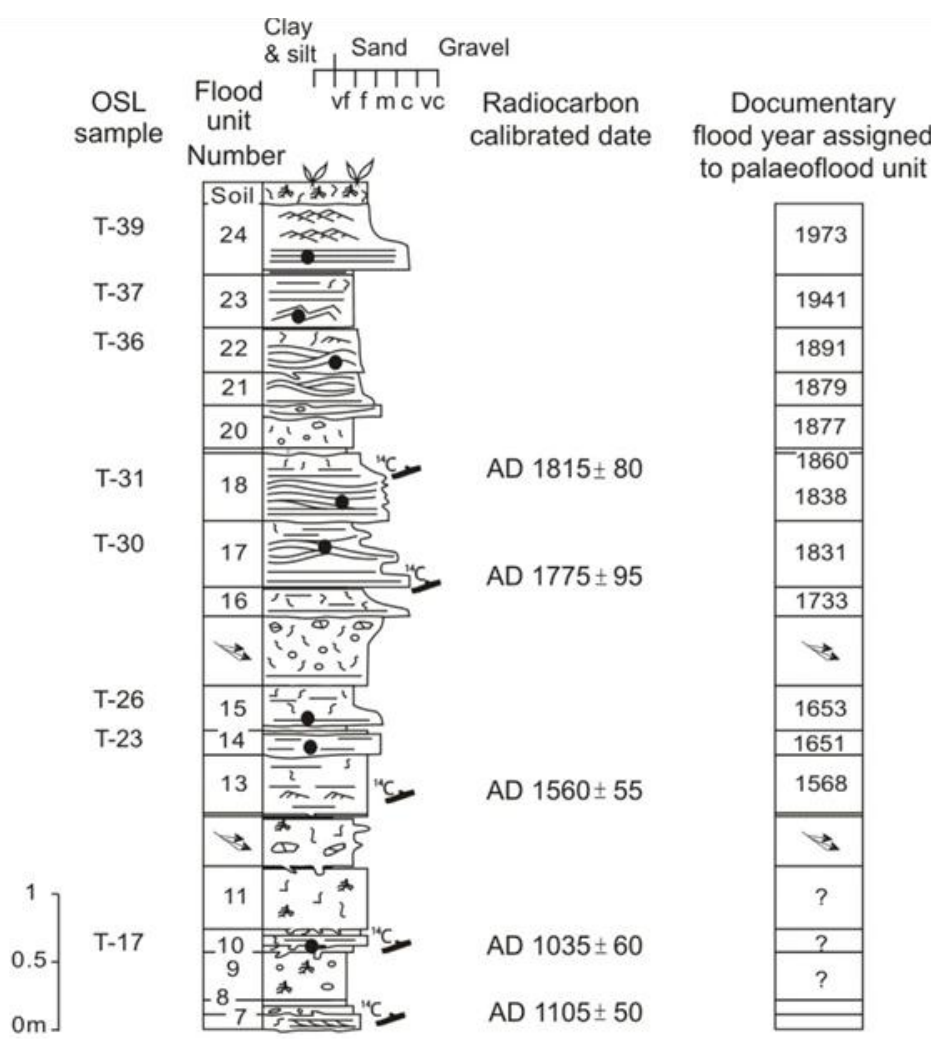

Figure 1. Site location, section and age range association. Position of the eight samples taken for OSL measurements are shown on the section (black dots). Flood year assigned from documentary records and the five radiocarbon dates available are also shown.

\section{LEGEND}

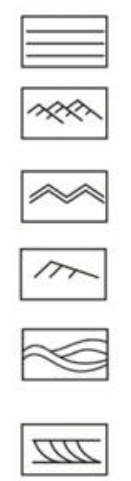

Parallel lamination

Climbing ripples

Climbing ripples

In phase

Ripples lamination

Hummoky

Cross bedding

Planar (2d)

Cross bedding

\section{Colluvium}

$\mathrm{CO}^{\circ}$ (1) Carbonates

$\sim$ Mud cracks

R Roots

Ssss Bioturbation

Radiocarbon sample

- OSL sample 


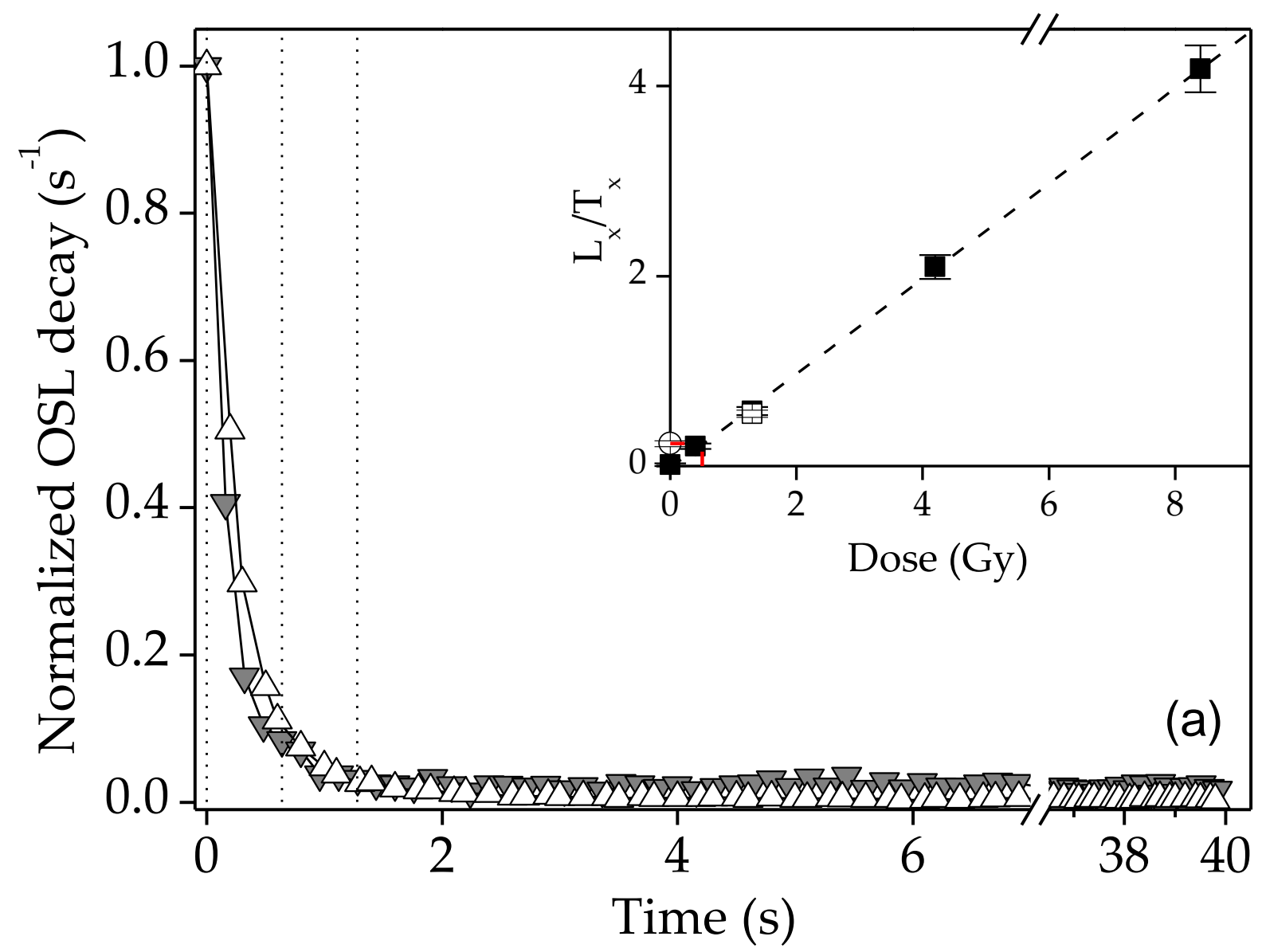

Figure 2a. Normalized natural OSL decay curve from a multi-grain aliquot of sample T-31 (solid downwards triangles) and a multigrain aliquot of calibration quartz (open upwards triangles). The summation intervals used (EBG) are indicated by the dotted lines. The inset shows the sensitivity corrected dose response curve fitted linearly. The recycling point is shown as an open square. The natural (open circle) is shown on the y-axis. 


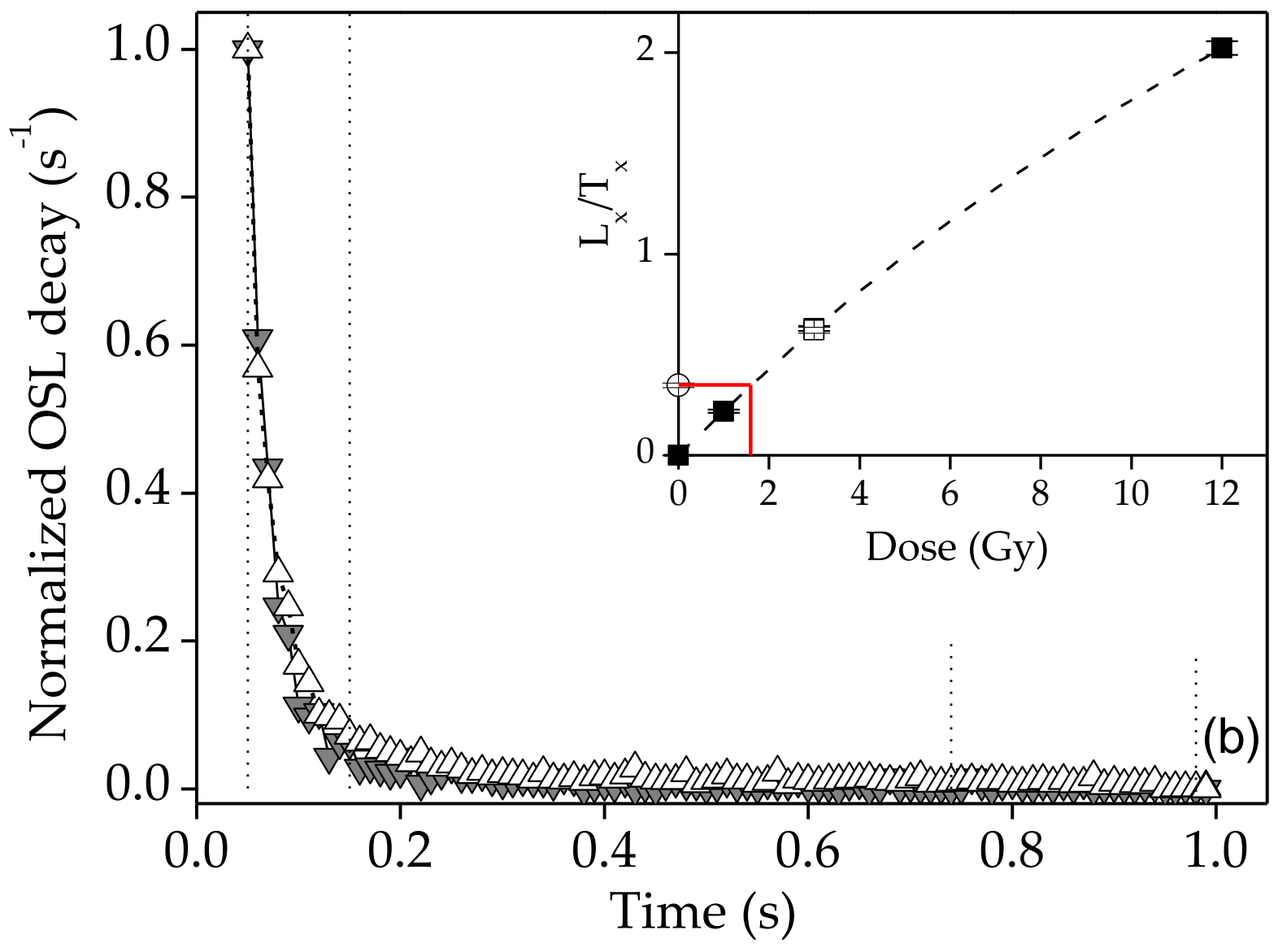

Figure 2b. Normalized natural OSL decay curve from a single grain of sample T-26 (solid downwards triangles) and a single grain of calibration quartz (open upwards triangles). The summation intervals used are indicated by the dotted lines. The inset shows the dose response curve fitted with a saturating exponential function. 
Figure 3. Cumulative light sum against the proportion of grains for the natural (dashed line) and the 3 Gy regeneration dose (solid line) signal obtained from the 3600 grains measured from sample T-26. The 1:1 represents the "ideal" case where all grains contribute equally to the light sum.

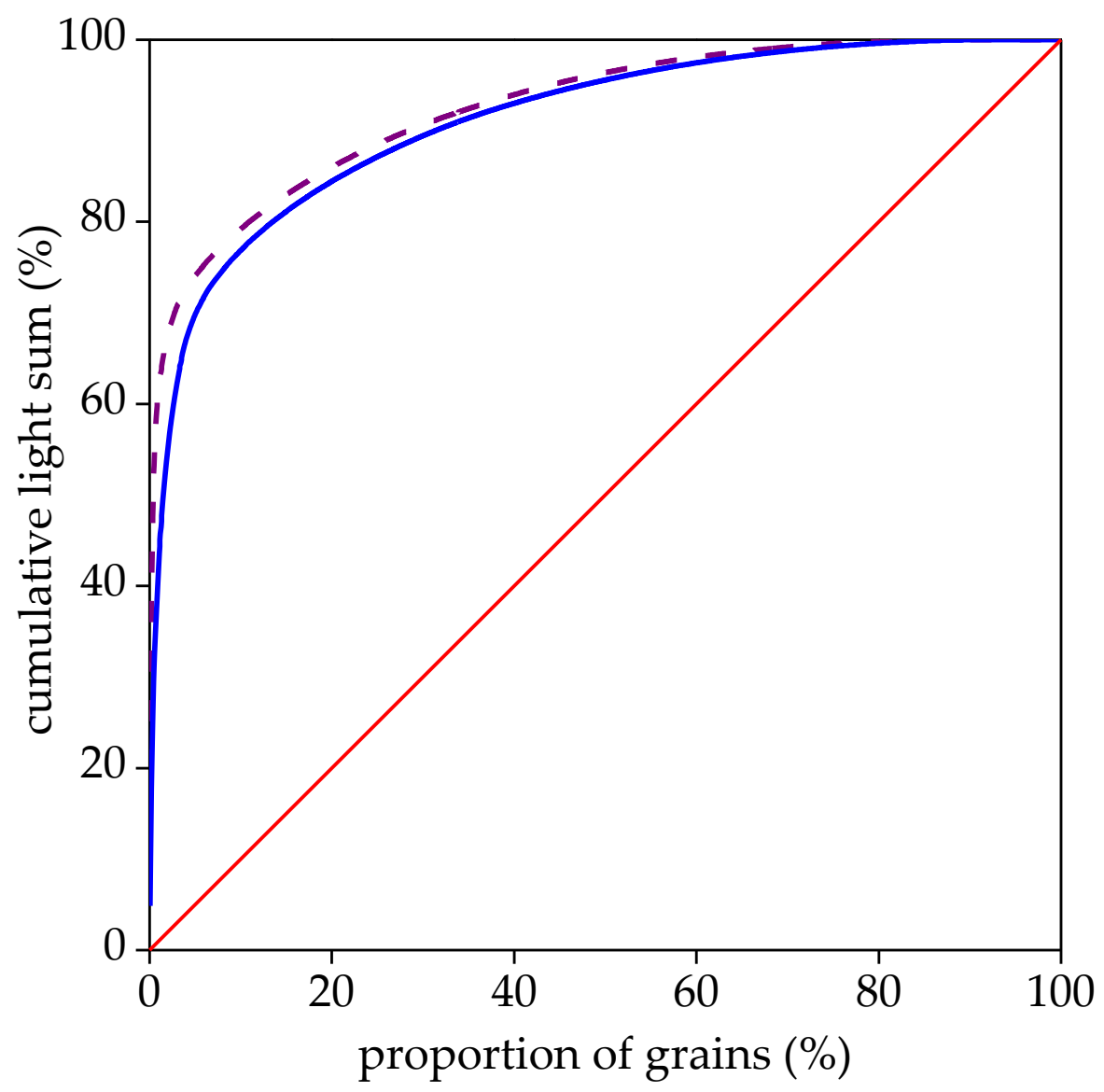




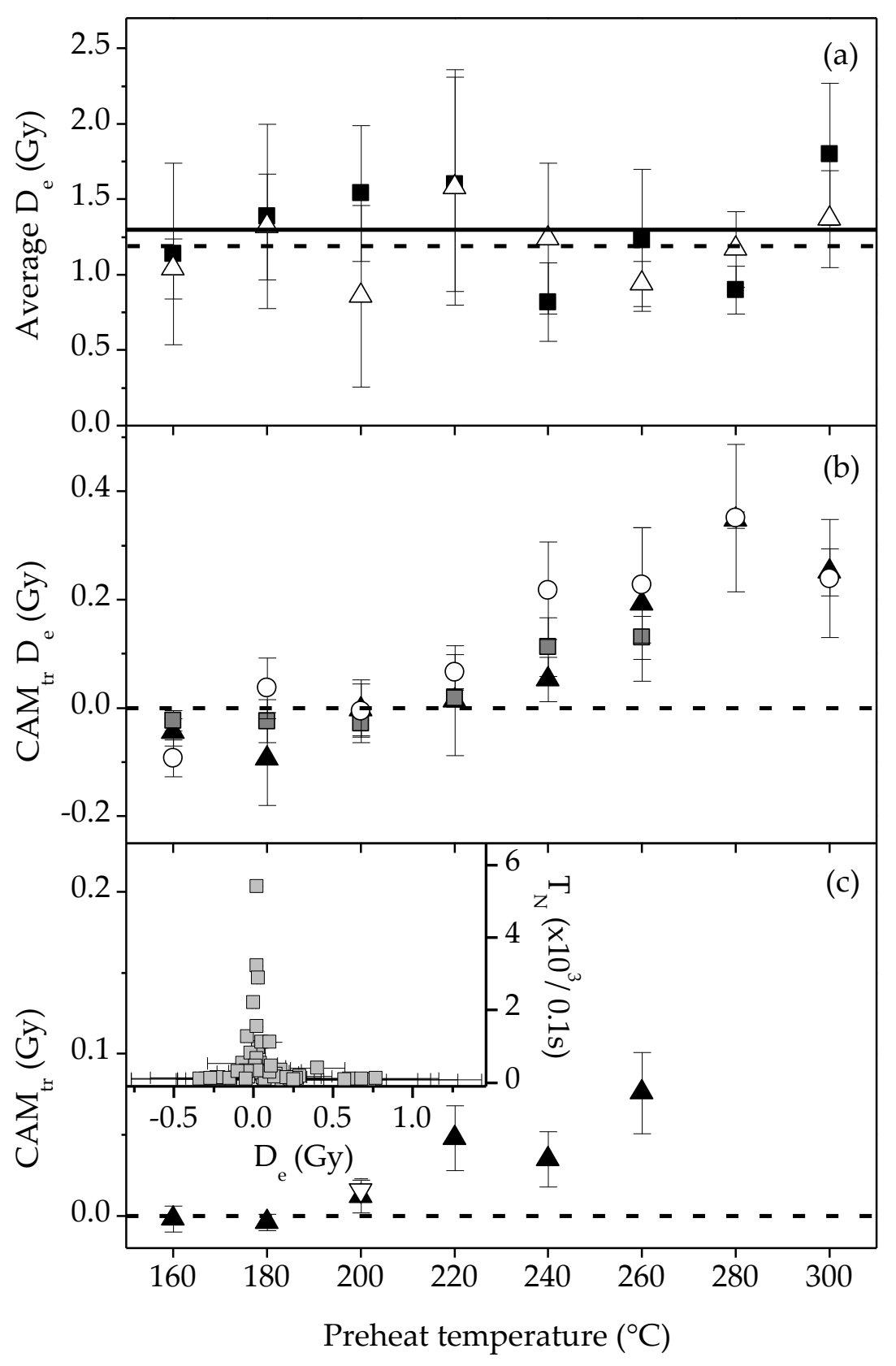

Figure 4. (a) Preheat plateau results from multi-grain aliquots of samples T-23 (squares) and T-39 (open triangles). The cutheat temperature was $20^{\circ} \mathrm{C}$ less than the applied preheat temperature. Points and error bars correspond to the average and standard error of 6 individual dose estimates. The overall average and standard error are $1.30 \pm 0.12$ Gy and $1.19 \pm 0.08$ Gy for T-23 (solid line) and T-39 (dashed line), respectively. All dose estimates are consistent with the overall average within 2 standard errors showing no significant offsets at higher temperatures. (b) Thermal transfer results from laboratory bleached aliquots of samples T-17 (triangles), T-26 (squares) and T-39 (open circles). Individual points correspond to the average of 6 independent dose estimates for each temperature. Thermal transfer only appear to become significant for temperatures above $240^{\circ} \mathrm{C}$. (c) $\mathrm{CAM}_{\mathrm{tr}}$ results from thermal transfer laboratory blue light bleached single grains from sample T-30 (upwards solid triangles, $\sim 30$ grains per dose estimate). The dose derived from solar simulator (Hönle Sol 2) bleached single grains of sample T-39 using a preheat temperature of $200^{\circ} \mathrm{C}$ is also shown (downwards open triangle). The inset shows the dose distribution obtained for the bleached portion of sample T-39 using a preheat temperatur of $200^{\circ} \mathrm{C}$. 


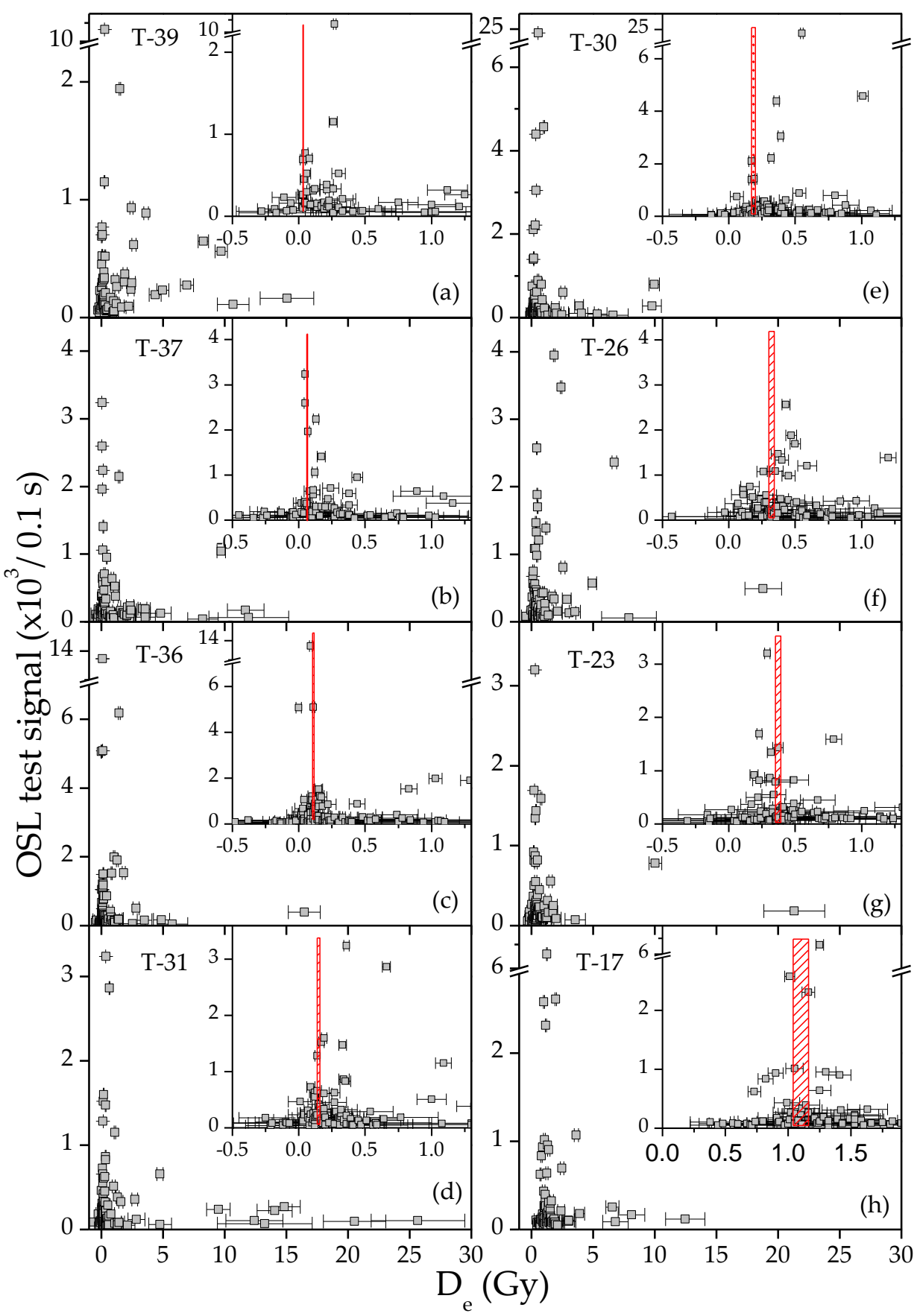

Figure 5. Single grain dose distributions from the eight samples measured using the SAR protocol. We show the signal of the natural test dose as a function of measured dose. The insets show the same data for doses less than 1.3 Gy except for T-17 where doses less than 1.9 Gy are shown. The expected doses are indicated by the vertical red line/bar. These expected doses are derived from the ages provided by the independent age control multiplied by the measured quartz dose rate given in Table 1 . 


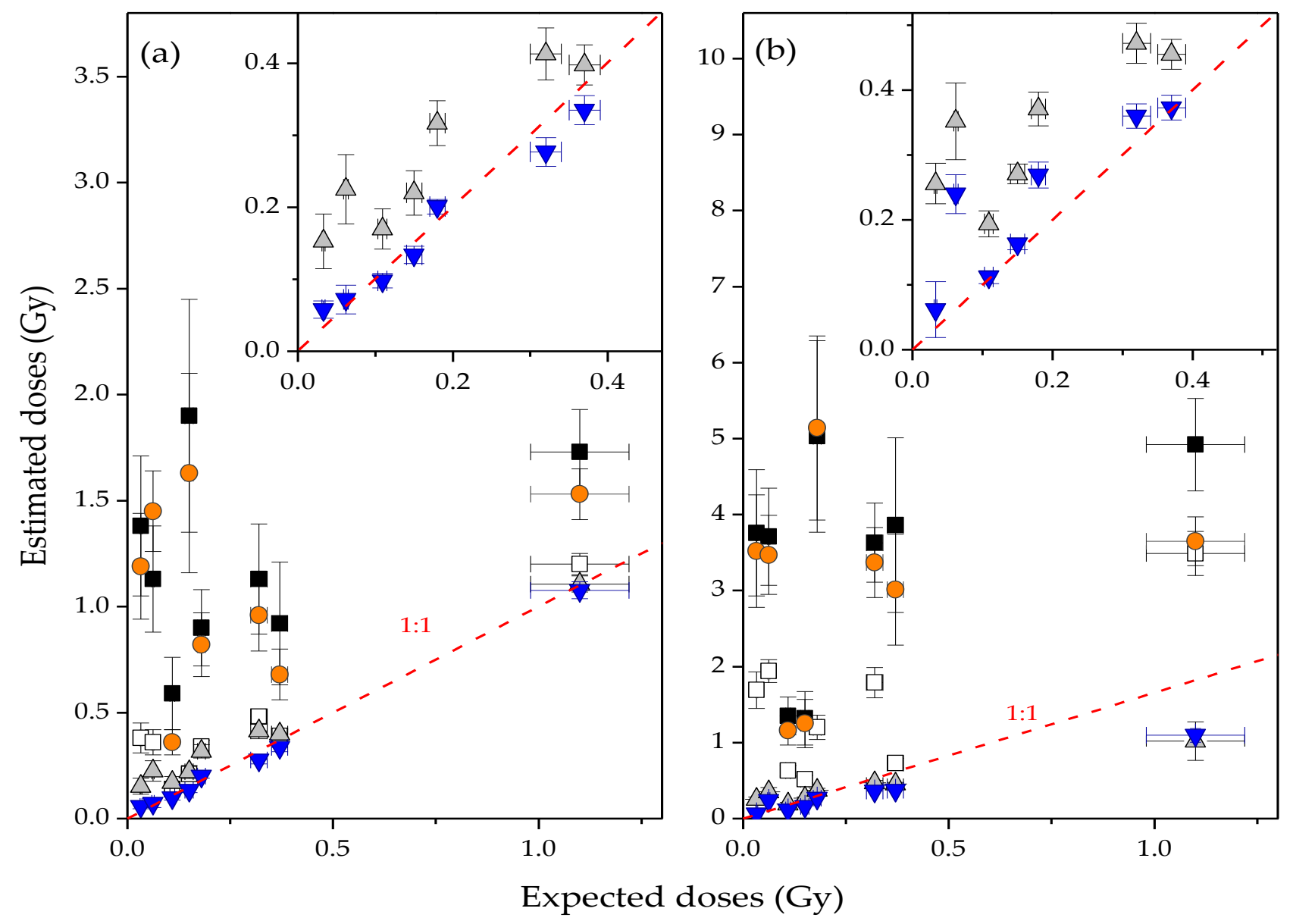

Figure 6. Estimated doses using (a) single grains and (b) multi-grain aliquots versus expected doses. Doses have been estimated using the simple average (solid squares), the robust average (open squares), $\mathrm{CAM}_{\mathrm{tr}}$ (solid orange circles), $\mathrm{MAM}_{\mathrm{tr}}$ (upward gray triangles) and IEU (downward blue triangles). Insets show a close up of the burial dose estimates for the seven youngest samples using MAM $_{\text {tr }}$ and IEU. The 1:1 line (dashed) is also shown. 


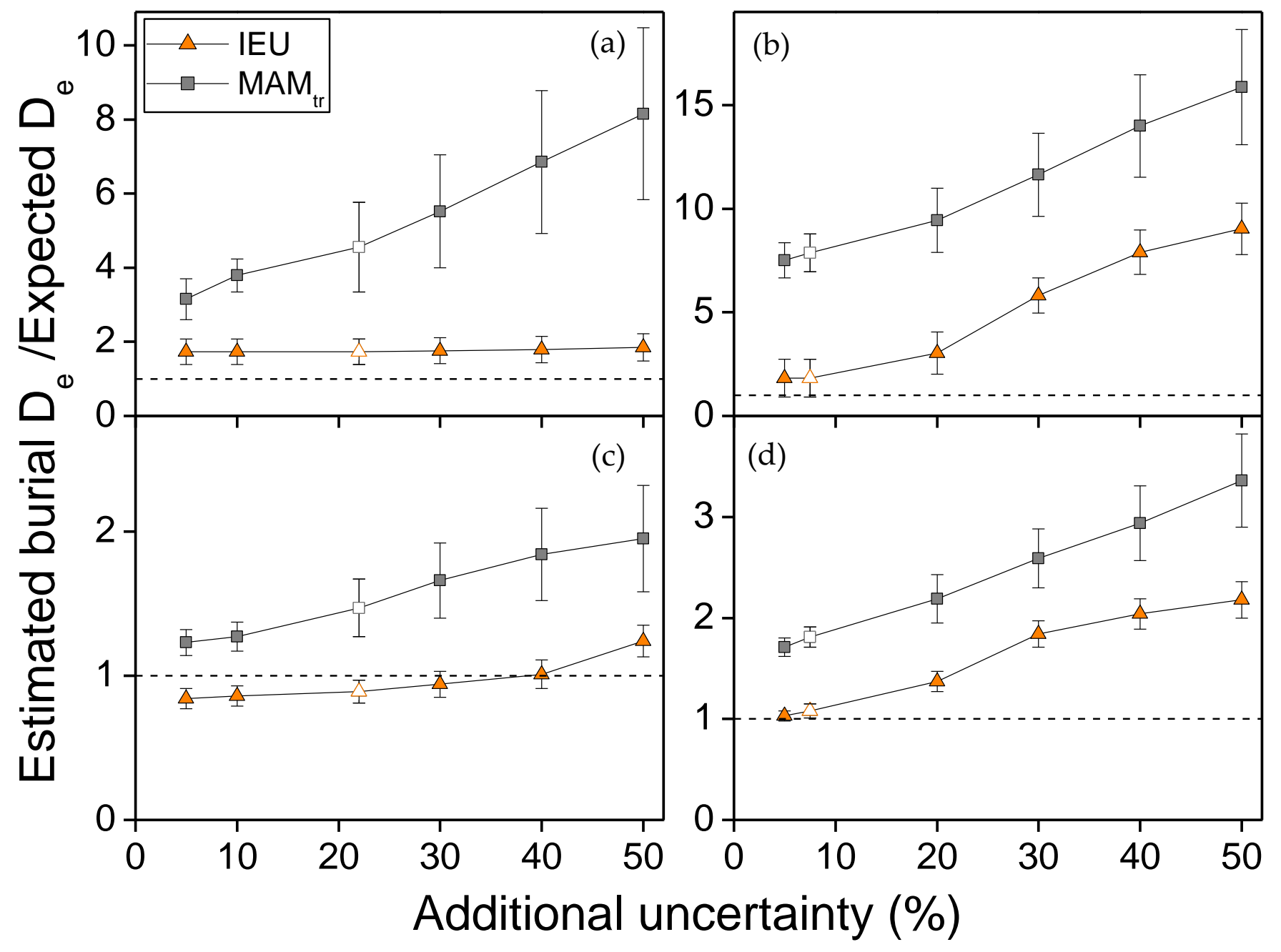

Figure 7. Ratio of estimated minimum burial dose and the expected dose as a function of additional uncertainty assigned to individual dose estimates for sample T-39 (a and b) and T-31 (c and d) using MAM $_{\mathrm{tr}}$ (squares) and IEU (triangles). (a) and (c) are derived from measurements using single grains; (b) and (d) are derived from multi-grain measurements. The open symbols indicate the burial dose estimates obtained using the additional uncertainty value derived from the gamma dose recovery experiments. 


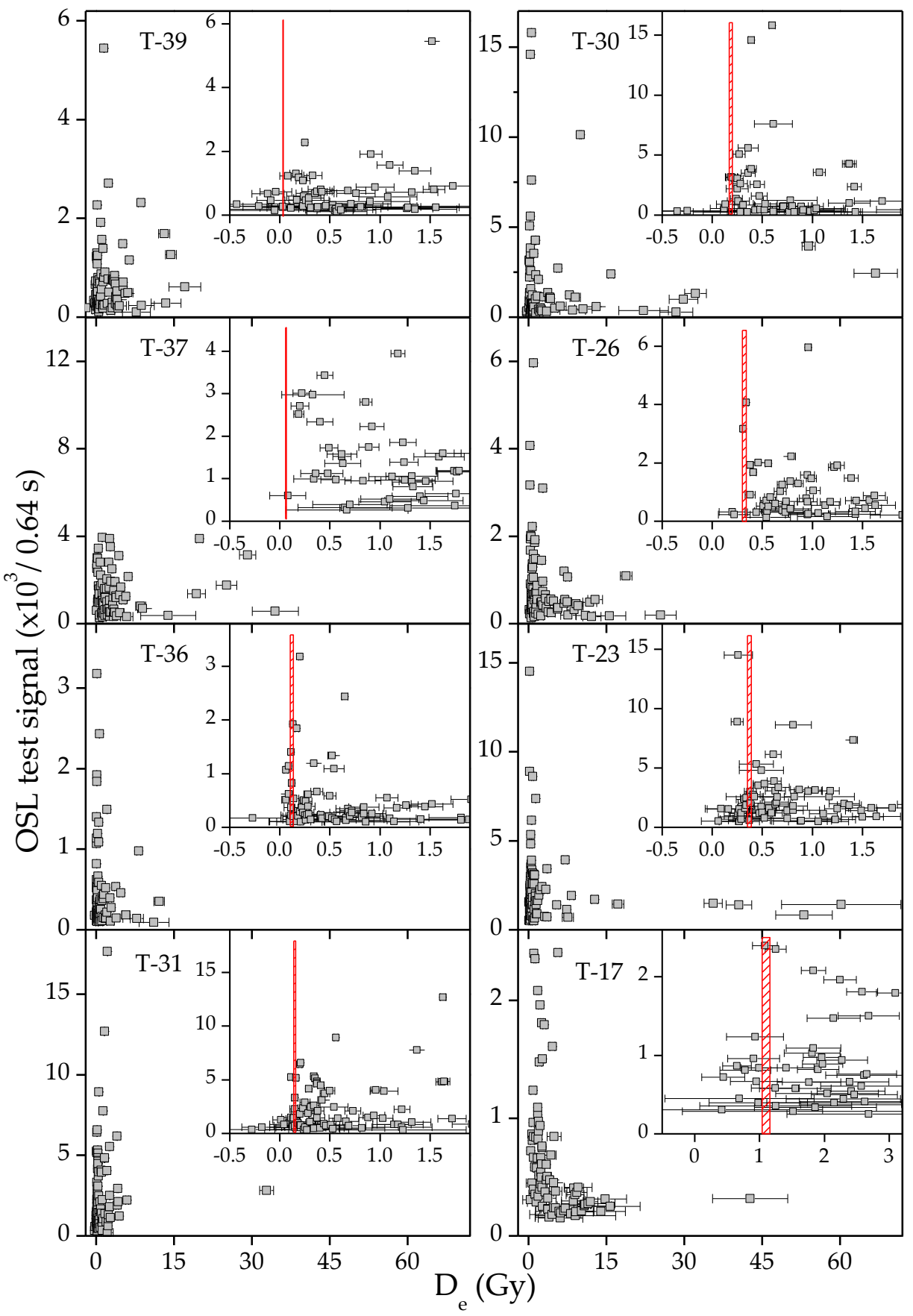

Figure 8. Multi-grain aliquot dose distributions from the eight samples measured using the SAR protocol. The signal of the natural test dose is plotted as a function of the measured dose. The insets show the same data from doses less than $1.8 \mathrm{~Gy}$ except for T-17 where doses less than $3.2 \mathrm{~Gy}$ are displayed. The expected doses are indicated by the vertical red line/bar. 


\begin{tabular}{c|cccccccc} 
Sample & Depth $(\mathbf{c m})$ & $\begin{array}{c}\text { Water } \\
\text { content }(\%)\end{array}$ & ${ }^{226} \mathbf{R a}(\mathbf{B q} / \mathbf{k g})$ & ${ }^{232} \mathbf{T h}(\mathbf{B q} / \mathbf{k g})$ & ${ }^{\mathbf{4 0}} \mathbf{K}(\mathbf{B q} / \mathbf{k g})$ & $\begin{array}{c}\text { Total dose rate } \\
(\mathbf{G y} / \mathbf{k a})\end{array}$ & $\begin{array}{c}\text { Expected ages } \\
(\mathbf{k a})\end{array}$ & $\begin{array}{c}\text { Expected } \\
\mathbf{d o s e s}(\mathbf{G y})\end{array}$ \\
\hline T-39 & 59 & 8.7 & $13.3 \pm 0.4$ & $7.2 \pm 0.3$ & $91.4 \pm 4.9$ & $0.82 \pm 0.04$ & 0.04 & $0.033 \pm 0.002$ \\
T-37 & 95 & 11.8 & $14.1 \pm 0.3$ & $9.6 \pm 0.3$ & $116.6 \pm 3.2$ & $0.90 \pm 0.05$ & 0.069 & $0.062 \pm 0.003$ \\
T-36 & 122 & 2.6 & $14.1 \pm 0.5$ & $11.6 \pm 0.5$ & $135.0 \pm 6.3$ & $0.91 \pm 0.05$ & 0.119 & $0.109 \pm 0.006$ \\
T-31 & 216 & 9.7 & $15.0 \pm 0.5$ & $8.5 \pm 0.5$ & $100.9 \pm 5.9$ & $0.85 \pm 0.05$ & 0.172 & $0.146 \pm 0.009$ \\
T-30 & 259 & 3.4 & $13.7 \pm 0.5$ & $8.4 \pm 0.5$ & $141.7 \pm 6.8$ & $1.00 \pm 0.06$ & 0.179 & $0.179 \pm 0.010$ \\
T-26 & 351 & 2.0 & $14.3 \pm 0.5$ & $8.6 \pm 0.5$ & $112.8 \pm 5.9$ & $0.91 \pm 0.05$ & 0.357 & $0.32 \pm 0.02$ \\
T-23 & 367 & 8.4 & $14.0 \pm 0.3$ & $9.9 \pm 0.3$ & $113.9 \pm 3.5$ & $0.84 \pm 0.05$ & 0.442 & $0.37 \pm 0.02$ \\
T-17 & 478 & 13.4 & $14.4 \pm 0.3$ & $12.6 \pm 0.4$ & $200.3 \pm 4.9$ & $1.13 \pm 0.05$ & $0.98 \pm 0.06$ & $1.10 \pm 0.12$
\end{tabular}

Table 1. Summary of sample depth, estimated water content and radionuclide concentrations used to calculate the total quartz dose rate. The water content was measured immediately after sampling and is considered representative for the burial time. An absolute error of $4 \%$ is assumed. Uncertainties represent one standard error. An internal quartz dose rate of $0.06 \pm 0.03 \mathrm{~Gy} / \mathrm{ka}$ has been assumed. No uncertainties are reported for the expected ages as they are based on detailed historical records, e.g. they are known to a precision of days. The exception to this is sample T-17 where the expected age is based on radiocarbon dating (see text for details). 


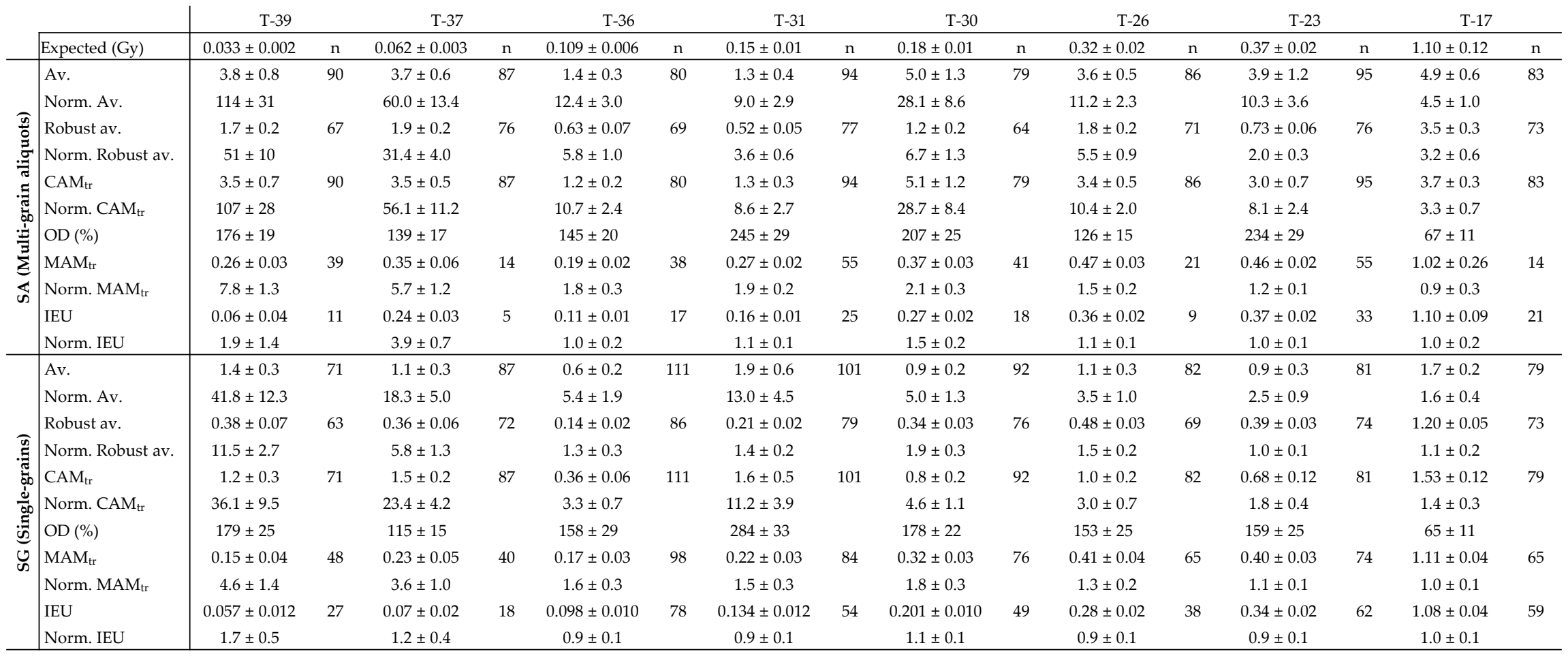

Table 2. Summary of burial doses for both multi-grain small aliquots (SA) and single-grains (SG). "Expected" is the dose expected from independent age control. The uncertainties assigned to the expected dose is derived from the uncertainties assigned to the respective dose rates. The uncertainty assigned to sample T-17 also contains the uncertainty assigned to the radiocarbon date. "Av." is the simple unweighted average and "Robust av." is that derived from robust statistics. $\mathrm{CAM}_{\mathrm{tr}}$ and $\mathrm{MAM}_{\mathrm{tr}}$ are the transformed version of the CAM and MAM approaches respectively. OD is the over-dispersion derived from $\mathrm{CAM}_{\mathrm{tr}}$ IEU is the internal/external consistency criterion. The ratio between each result and the dose expected from the independent age control are summarized as "Norm.". The number of aliquots (n) used in each case is also given. 


\begin{tabular}{ccccc} 
Sample & Depth $(\mathbf{c m})$ & Preferred ages & Expected ages & $\begin{array}{c}\text { Estimated/Expected } \\
\text { age ratio }\end{array}$ \\
\hline T-39 & 59 & $0.07 \pm 0.02$ & 0.040 & $1.8 \pm 0.4$ \\
T-37 & 95 & $0.08 \pm 0.02$ & 0.069 & $1.2 \pm 0.3$ \\
T-36 & 122 & $0.11 \pm 0.01$ & 0.119 & $0.90 \pm 0.11$ \\
T-31 & 216 & $0.16 \pm 0.02$ & 0.172 & $0.92 \pm 0.10$ \\
T-30 & 259 & $0.20 \pm 0.02$ & 0.179 & $1.12 \pm 0.09$ \\
T-26 & 351 & $0.31 \pm 0.03$ & 0.357 & $0.85 \pm 0.08$ \\
T-23 & 367 & $0.40 \pm 0.03$ & 0.442 & $0.90 \pm 0.07$ \\
T-17 & 478 & $0.96 \pm 0.06$ & $0.96 \pm 0.06$ & $0.98 \pm 0.06$
\end{tabular}

Table 3. Summary of the preferred ages and the ratio of these ages and the ages expected from independent age control. The preferred ages are based on the burial doses estimated using the IEU approach. 